Crpy
Nuwc TP 5

Sept. 67
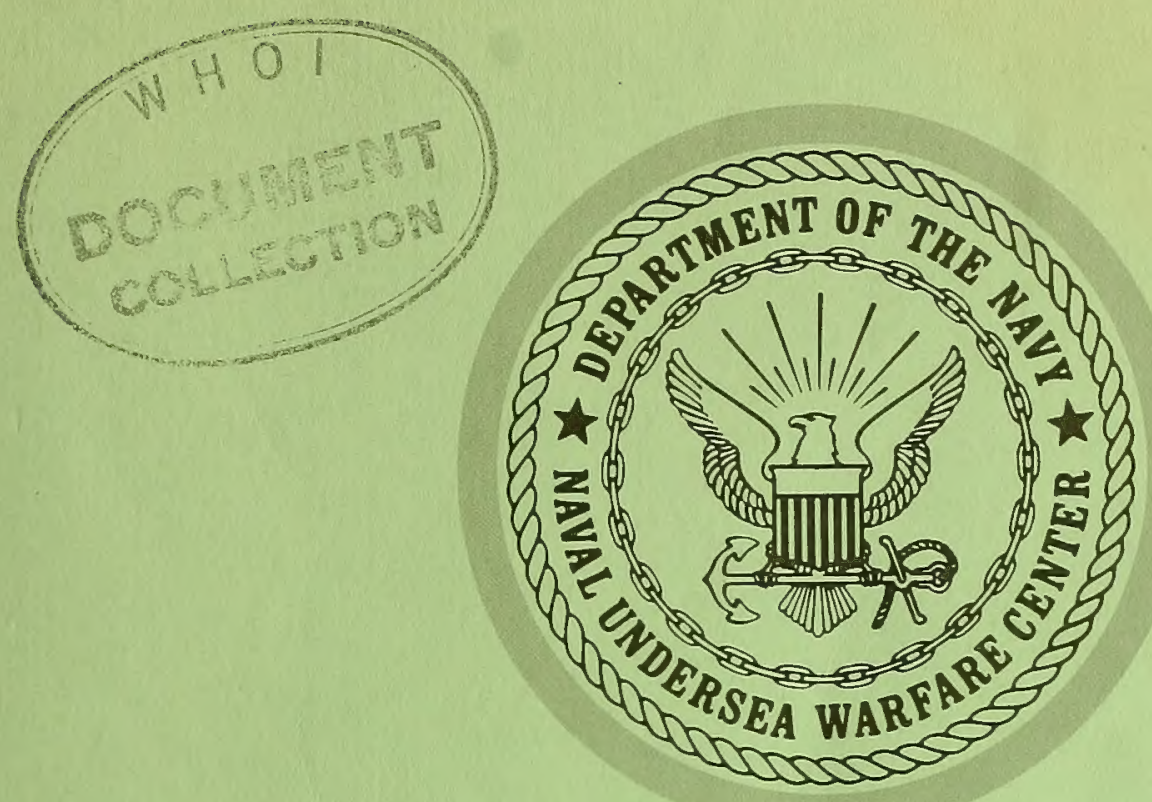

\title{
ПUW C
}

\section{FLOWMETERS \\ IN SHALLOW-WATER OCEANOGRAPHY}

\author{
By J.R. Olson
}

Ocean Sciences Department

San Diego, California

September 1967

GC

239

04

1967 


\section{NAVAL UNDERSEA WARFARE CENTER An activity of the Naval Material Command}

G. H. Lowe, Capt., USN

Commander
Wm. B. McLean, Ph.D.

Technical Director

The work described in this report was performed between September 1965 and June 1967 under SR 10403 01, Task 0580 (NEL L40471) by the Marine Environment Division at San Diego, California. This report was approved for publication

11 Julv 1067
W

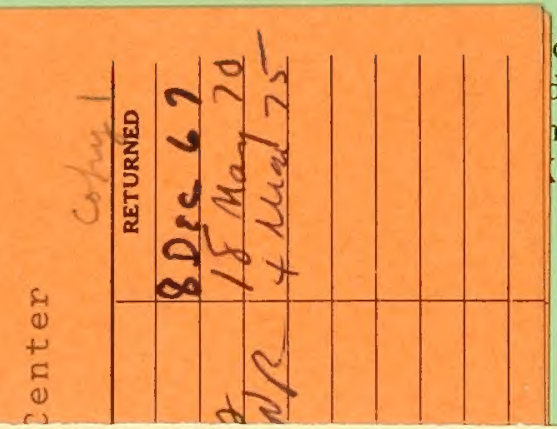

cussions and review of the d, Dr. P.G. Hansen, J. Grafa, nming by R.F. Arenz and eulegan and L.H. Carpenter, of 16.

Under authority of

G.H. Curl, Head Ocean Sciences Dept. 


\section{PROBLEM}

Investigate and report on factors in physical oceanography which pertain to underwater sound, including physical properties such as sound velocity, thermal structure, and water motion. Specifically, determine the type of shallow-water flowmeter best suited for measuring low level, steady-state currents in the presence of orbital velocity motion due to surface waves.

\section{RESULT}

No known commercial meters are available for accurate measurements of this type. The electromagnetic method is believed to be inherently the best approach to the problem.

\section{RECOMMENDATIONS}

1. Investigate new configurations using ac fields that will

(a) provide minimum hydrodynamic interference,

(b) measure flow over large distances.

2. Experimentally determine the directional response of the "tube" configuration.

3. Consider using the earth's field type flowmeter, but only if a feature for zeroing is employed. 



\title{
CONTENTS
}

\author{
INTRODUCTION . . p page 5 \\ PROCEDURES . . . 5 \\ Selection ... 5 \\ Operation ... 5 \\ REQUIREMENTS . . . 6 \\ FLOWMETERS . . . 7 \\ Acoustic . . . 7 \\ Impellor . . 10 \\ Electromagnetic . . 15 \\ Drag Force . . 23 \\ LAGRANGIAN METHOD . . . 38 \\ Short-Distance Tracers . . 40 \\ MISCELLANEOUS . . . 40 \\ Savonius Rotor Meters ... 40 \\ Thermo-Anemometer Meters . . . 40 \\ CONCLUSIONS . . . 41 \\ RECOMMENDATIONS . . 41 \\ REFERENCES . . . 42
}

\section{ILLUSTRATIONS}

1 Time-difference acoustic meter, one path ... page 8

2 Time-difference acoustic meter, two paths ... 8

3 Doppler acoustic meter . . 9

4 Calibration curve, Marine Advisers Inc. ducted meter model B-7C . . 10

5 Marine Advisers Inc. ducted meter model B-7C . . 11

$6 \quad$ Nonlinear distortion, impellor meter . . 13

7 Directional response of Marine Advisers Inc. ducted current meter Q -8 . . 15

8 Transverse magnetic field configuration, electromagnetic flowmeter . . 16

9 Noncosine directional response, linear output example . . 18

10 False de levels due to noncosine angular response . . .21

11 Variation of drag coefficient of cylinders . . 25

12 Variation of inertia coefficient of cylinders . . 26

13 Example of variation of the inertia and drag coefficients of a cylinder during a wave cycle ...27 


\section{Illustrations (Continued)}

14 Example of variation of the inertia and drag coefficients of a cylinder during a wave cycle ...27

15 Example of variation of the inertia and drag coefficients of a cylinder during a wave cycle ...28

16 Variations of the magnitude and phase of the maximum force on cylinders . . 29

17 Drag force current meter . . . 31

18 Recorder sample during run 2 (north-south) ... 31

19 Recorder sample during run 1 (east-west) . . 32

$20 \quad$ Schematic drawing of beam and cylinder . . 32

21 Drag force current meter example . . 33

22 Drag force current meter example . . 34

$23 \mathrm{AC}+\mathrm{DC}$ flow throughout one wave cycle where inertial term may be neglected and drag coefficient is constant; drag force current meter . . 3 35

24 Drag force meter example . . . 37 


\section{INTRODUCTION}

Flowmeters are not normally designed for the purpose of measuring shallowwater, steady-state currents in the presence of orbital velocities. A need therefore exists for information on the value of existing meters used for this purpose.

This report presents a feasibility study of the relative merits of various instruments and techniques. The dynamic response, filtering, linearity, and directionality of various devices were investigated to identify the most accurate flowmeter to employ at depths where the magnitude of orbital velocities caused by surface waves can be several times larger than steady-state flows.

\section{PROCEDURES}

\section{Selection}

Typical magnitudes of orbital velocities are from 5 to 50 centimeters per second $(\mathrm{cm} / \mathrm{sec})$ with periods from 10 to 15 seconds. Typical steady-state signals are actually very-low-frequency velocity fluctuations. Typical magnitudes are from 2 to $10 \mathrm{~cm} / \mathrm{sec}$ with periods of interest at 5 to 10 minutes and at semidiurnal and diurnal regions. Since the frequency of these oscillations is so low compared with the predominant orbital or swell frequencies, they may be considered dc or steady-state signals for most analytical work.

The primary concern will be the selection of a transducer with inherently good features for this particular type of measurement. Of secondary concern will be items such as the amount of electronic equipment required or the necessary power and maintenance. The accessibility of flowmeters installed in shallow water (compared, for example, with deep-water buoy installations) allows more flexibility in the specifications. If sizable amounts of electronic equipment needing ac power are required, this will not be considered an inherent bad feature of the system. However, if the electronic package has to be so close to the sensor that it interferes hydrodynamically with the flow, then it would become an inherent fault.

\section{Operation}

Two basic procedures, continuous and discrete, can be used operationally for the measurement of the velocities of currents. The continuous method can use a transducer: 
1. With frequency response from zero to above the swell frequency; all data are recorded and the swell data removed later.

2. As in 1., but with swell frequencies filtered out between transducer and recorder. tion filter).

3. That filters out the swell frequency and records all other data (rejec-

4. That passes only signals with frequencies lower than that at the swell (low pass filter).

The best approaches would be 3 . and 4 . because the filtering is done at the earliest possible stage and a roughly flat spectrum is recorded. The choice of upper frequency cutoff is based on highest frequency of interest and highest frequency recorded. ${ }^{1}$ A typical ratio is $2: 1$. There would be little difference in data recorded in 3 . and 4 . because of the low energy content of the spectrum above the swell frequency. Approach 1 . is undesirable because of the small signal-to-noise ratio and large amount of data to record and reduce.

The discrete method can be imposed (either after recording or in real time) or inherent. Inherent discreteness is found by timing particles traveling over known distances. Care must be exercised in choosing the sampling interval so that aliasing does not occur.

\section{REQUIREMENTS} follows:

The characteristics and conditions for a successful flowmeter are as

1. Outputs with orthogonal components, or a capacity to measure the velocity directly with outputs for magnitude and angle; resultants in the horizontal plane are sufficient, but three-dimensional types are more desirable.

2. Measurement errors of the steady-state value less than 5 percent.

3. A low-temperature coefficient needed because many of the signals of interest are associated with large temperature changes -5 to $10^{\circ} \mathrm{C}$ are typical.

4. Meter mounts affixed to the sea bottom or stationary structures to prevent motion relative to the earth; errors resulting from mounting to buoys are not considered. ${ }^{2}$

5. Large dynamic velocity range.

6. Bidirectional response, the angular response preferably a cosine function. 
7. Linear output.

a. Dc levels not connected with swell amplitudes. Because nonlinearities are a function of amplitude, the swell magnitude can generate different, false dc signals in some cases. This is particularly important when looking at diurnal signals.

b. Intermodulation distortion from nonlinearities, where more than one strong frequency is present in the natural spectrum, should be low.

8. Long-term stability. The ability to check and adjust (or record) the zero and sensitivity is a necessary feature.

9. Electrical output.

10. Size that will permit testing in tow tanks.

\section{FLOWMETERS}

\section{Acoustic}

Acoustic flowmeters are of two basic kinds: (1) those that measure time difference of sound travel between two points, ${ }^{3,4}$ and (2) those that measure the Doppler shift. ${ }^{5,6}$

\section{TIME DIFFERENCE}

Two transducers, alternately radiator and receiver, permit finding the difference in transmission time for the two directions (fig. 1). Two radiators and two receivers allow pulses to be sent simultaneously in both directions (fig. 2); two closely spaced, parallel acoustic paths are used.

A desirable feature of acoustic meters is their lack of moving parts. Output linearity is better than 1 percent and with this type is independent of the speed of sound in the medium assuming identical acoustic paths. With meters using only two transducers, this assumes the same acoustical path for a time duration greater than the double transmission time. In two parallel paths, this assumes identical conditions over the enclosed space during the simultaneous transmission time. Under conditions of strong thermal gradients, instantaneous velocity errors up to 10 centimeters per second may occur. ${ }^{4}$ 


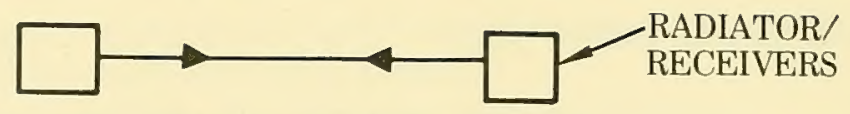

Figure 1. Time-difference acoustic meter, one path.

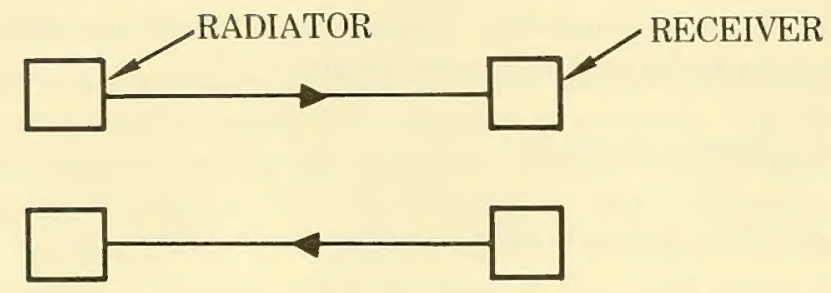

Figure 2. Time-difference acoustic meter, two paths.

Such temperature gradient effects would be serious if the meter were used to measure velocities associated with internal waves. Apparent velocity changes could be caused by the temperature gradients associated with the internal waves. The use of a meter with two transducers and a single path reduces this error. The typical ranges are from a few tenths of a centimeter per second to several hundred and overall accuracies 1 to 2 percent of full scale. However, there is a requirement for stable, expensive electronics because the differences in transit time are generally less than a microsecond. The instrument is inherently capable of sensing direction as well as magnitude of flow, but its use in oscillating flow can be severely limited by flow disturbance. Vortex shedding from the transducers produces high-frequency velocity fluctuations. Some meters may be zeroed in the field in the presence of flow, a necessary requirement for long-term measurements.

\section{DOPPLER SHIFT}

The Doppler acoustic meter depends on volume reverberation and a resulting frequency shift (fig. 3). Acoustical energy is transmitted in a narrow beam from one transducer. A receiving transducer having a similar beam pattern is positioned so that the two beams overlap. Typical volumes intersected are a few cubic centimeters at a distance of 50 centimeters from the transducers. The frequency of the reflected signal from the intersected volume filled with natural small scatterers is compared with the transmitted frequency. The average velocity of the scatterers is assumed to be that of the fluid. The frequency difference is proportional to the fluid speed in the direction of the beam. 


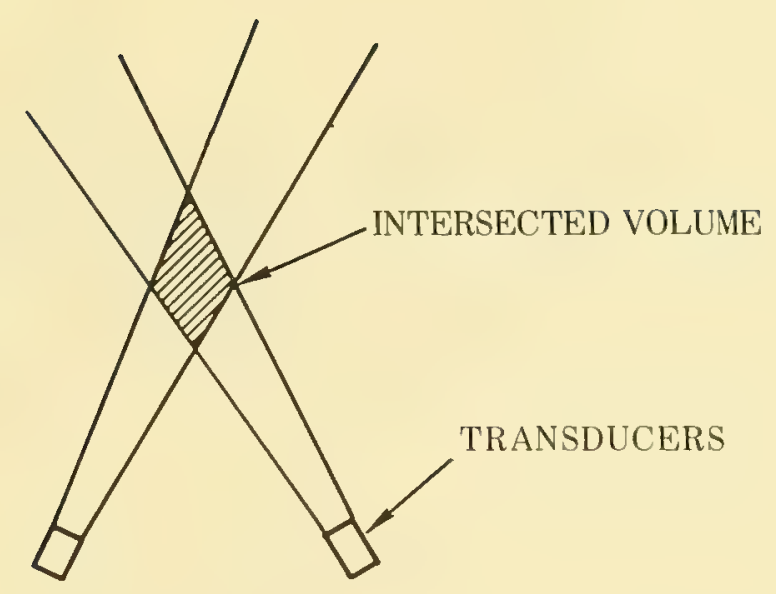

Figure 3. Doppler acoustic meter.

Transmitted frequencies must be very stable; with typical values from 3 to. 10 megacycles per second ( $\mathrm{Mc} / \mathrm{s}$ ), the resulting Doppler shift is only a few hundred cycles per second $(\mathrm{c} / \mathrm{s})$. The method is capable of determining direction as well as magnitude. In view of the meter measuring the velocity some distance from itself, little hydrodynamic disturbance might be expected, but this is only so when the meter is used in unidirectional flow and oriented to point into the flow. In oscillating flow, large distortions can result from disturbance of the flow about the case. Multiple sets of transducers mounted in a.symmetrical case could conceivably be used, but would complicate matters considerably.

Typical accuracies of the Doppler meter are 1 to 2 percent of full scale, and ranges are from a few tenths centimeters per second to several hundred. The computed flow rates are a function of the speed of sound, and corrections are needed. The directional response is unknown. The meter will respond to highfrequency fluctuations.

\section{SUMMARY}

The time-difference and Doppler-shift acoustic flowmeters are more suitable for constant-temperature, unidirectional flow, laminar or turbulent, than for the required need. Temperature effects (zero drift and multipath propagation); inability to measure and set the zero in some cases; hydrodynamic interference with the flow; and uncertain direction response pose serious problems. 


\section{Impellor}

Impellor meters, used widely by industry, are employed by oceanographers in a configuration consisting of an axial rotor mounted on bearings inside a length of tubing with circular cross section. On the rotor are equally spaced blades placed at some angle to the pipe axis. The pipe gives the meter a degree of directionality. The angular velocity of the rotor is a function of the current velocity. This angular velocity of the rotor is measured indirectly by photoelectric or magnetic pickups mounted on the pipe to sense the passage of the blades. The number of pulses per unit time obtained from such pickups are converted to rotor velocity.

The dynamic response for commercially available impellor meters is not given, but with low-mass rotors and low-entrained water mass, the response is sufficient for the required oceanographic conditions. ${ }^{7}$

A typical steady-state calibration curve furnished by Marine Advisers (fig. 4) is shown for their Model B-7C ducted current meter. Its specifications will be used for some calculations in order to determine if this type of meter is acceptable for the intended use. In order to depict the nature of the nonlinear output, figure 4 was replotted in figure 5 , using linear abscissa and ordinate scales. In the region of interest (below 1 knot), the nonlinearity is due mainly to a threshold. Between the threshold velocity and 1 knot the output is nearly linear.

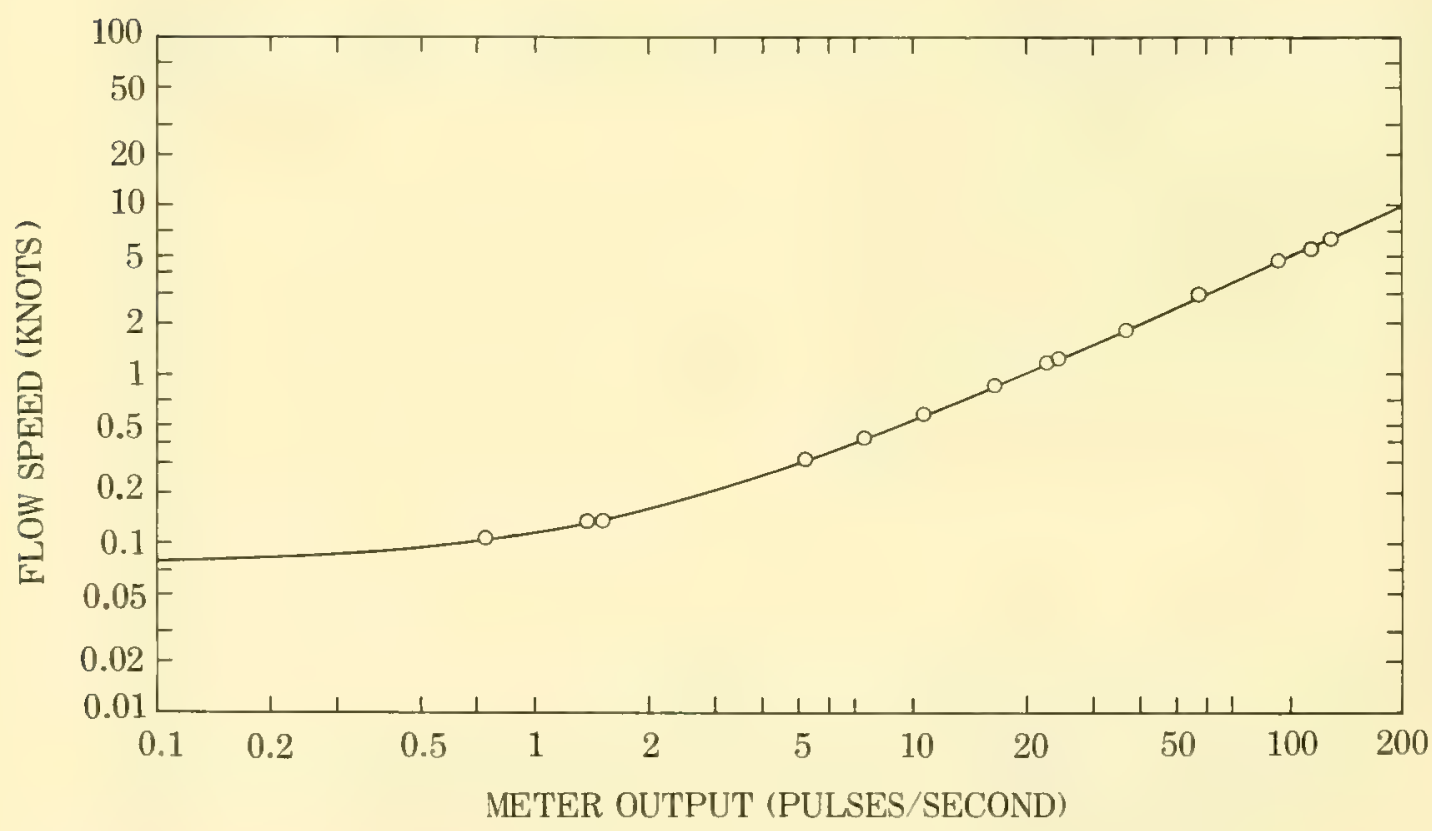

Figure 4. Calibration curve, Marine Advisers Inc. ducted meter model B-7C (five-bladed impeller); calibration date: 27 February 1963. 


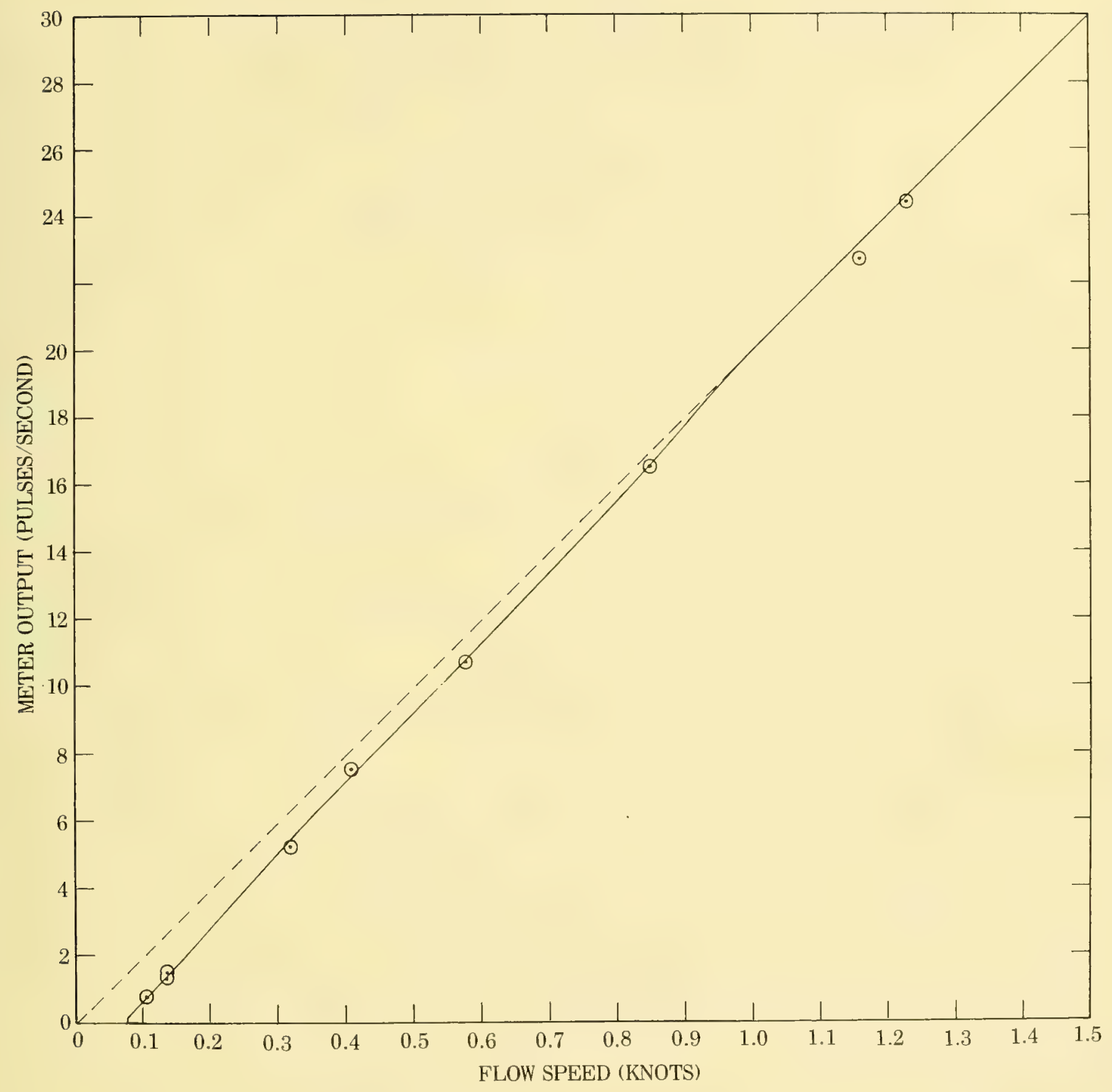

Figure 5. Marine Advisers Inc. ducted model B-7C (replotted from fig. 4). 
Consider a hypothetical example of the effect of this nonlinearity when extracting a de signal in the presence of an ac flow. Assume the ac flow is of low enough frequency so that the steady-state output calibration curve (figs. 4 and 5) will hold. For velocities under 1 knot, let the output, $e$, be given by

$$
\begin{aligned}
& e=K\left(U-U_{T}\right) \text { for } U>U_{T}>0 \\
& e=K\left(U+U_{T}\right) \text { for } U<-U_{T} \\
& e=0 \text { for }-U_{T}<U<U_{T}
\end{aligned}
$$

where

$$
\begin{aligned}
& K=\text { constant } \\
& U=\text { velocity } \\
& U_{T}=\text { threshold velocity }
\end{aligned}
$$

Let the actual velocity component, $U$, in the direction of the meter axis be

$$
U=U_{0}+U_{m} \sin \omega t
$$

where $U_{0}=\mathrm{dc}$ velocity component in direction of meter axis

$$
U_{m}=\text { amplitude of ac velocity component }
$$

Now for the case where $U_{0}>U_{T}$, the meter input and output appear as in figure 6 . The mean, or filtered, output $\bar{e}$, over one wave cycle can be found from

$$
\bar{e}=\frac{1}{2 \pi} \int_{0}^{A} K\left(U-U_{T}\right) d(\omega t)+\frac{1}{2 \pi} \int_{B}^{C} K\left(U+U_{T}\right) d(\omega t)+\frac{1}{2 \pi} \int_{D}^{2 \pi} K\left(U-U_{T}\right) d(\omega t)
$$

where

$$
\begin{aligned}
& A=\sin ^{-1}\left(\frac{U_{T}-U_{0}}{U_{m}}\right) \\
& B=\sin ^{-1}-\left(\frac{U_{T}+U_{0}}{U_{m}}\right) \\
& C=3 \pi-B \\
& D=3 \pi-A
\end{aligned}
$$




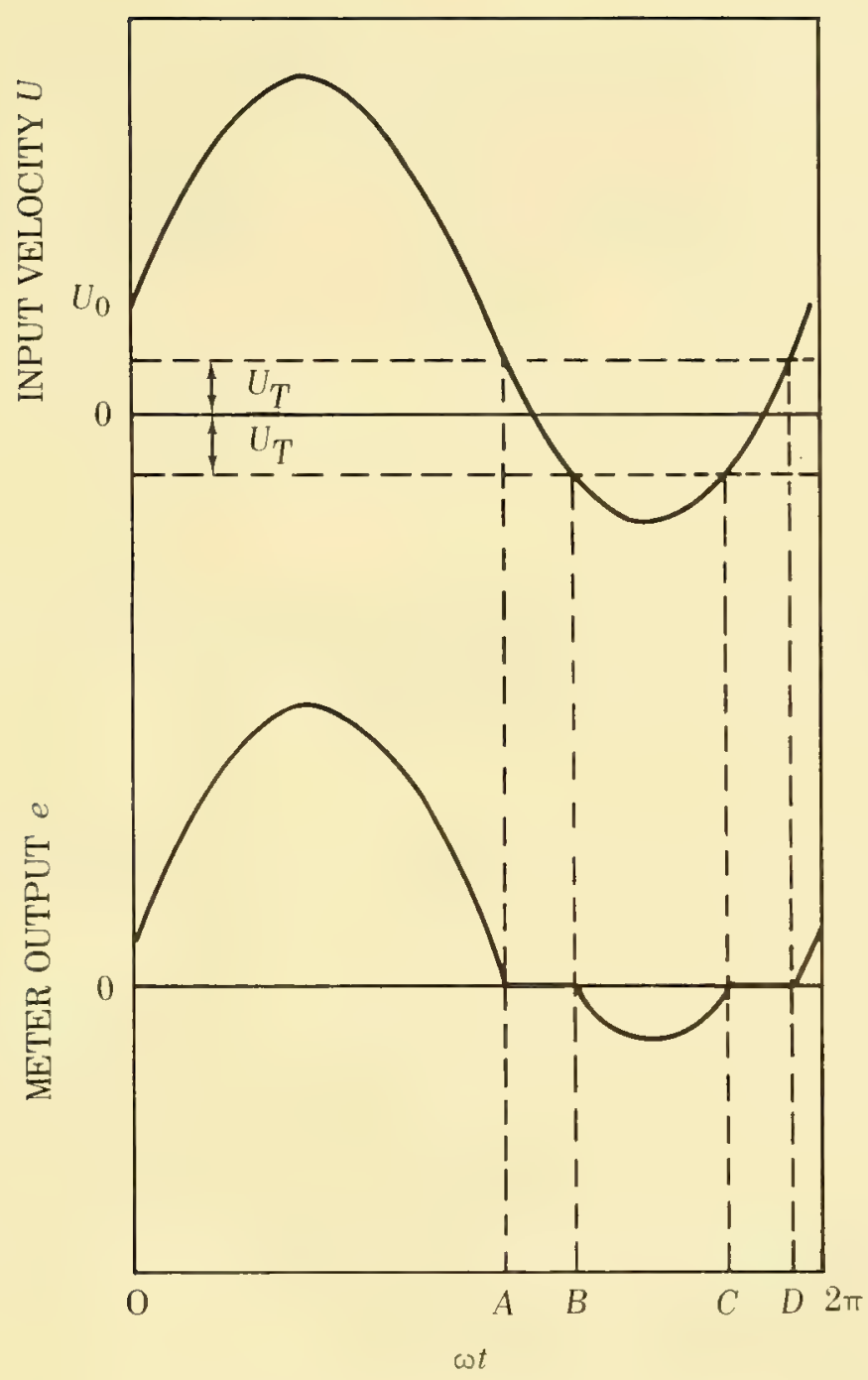

Figure 6. Nonlinear distortion, impellor meter.

$\bar{e}=\frac{K}{2 \pi}\left[U_{0}(A+C-B+2 \pi-D)+U_{T}(C-B-A-2 \pi+D)+U_{m}(\cos B-\cos C-\cos A+\cos D)\right]$

To find the mean velocity, $\bar{u}$, corresponding to the value of $\bar{e}$, a formula similar to equation (1) would be used. Solving for $\bar{u}$

$$
\bar{u}=\frac{\bar{e}+K U_{T}}{K}
$$

This would be the mean output of the real meter. It can then be compared with the velocity $U_{0}$. Although detailed curves are hard to plot because of the discontinuous nature of the output curve, a few values were calculated $\left(U_{T}=4 \mathrm{~cm} / \mathrm{sec} ; U_{0}\right.$ from 
5 to $15 \mathrm{~cm} / \mathrm{sec}$; and $U_{m}$ from 5 to $20 \mathrm{~cm} / \mathrm{sec}$ ). Resulting errors of 20 percent in $\bar{u}$ values were typical. This effect is due to the filtering of the nonlinear output with a nonzero average and is not a function of frequency. Since only the static calibration is used, it is not an inertial effect.

Steady-state linearity, threshold, and frequency response can be improved by various servo-controlled systems, ${ }^{8}$ however, modifications of this kind would be difficult under laboratory conditions and probably impossible in the ocean environment.

\section{ROTOR ROTATION}

The impellor flowmeter usually cannot sense direction of rotor rotation and is therefore unable to sense current direction. The outputs from the pickups are usually the same regardless of the direction of rotor rotation. Several methods for the solution of the problem exist; one is given by Koppe. ${ }^{9}$

\section{ANGULAR RESPONSE}

Figure 7 shows the angular response for the Marine Advisers Inc. Model Q-8 ducted meter, which will be considered typical for this kind of meter. The response is not a cosine function, and a single meter cannot be used to indicate the instantaneous component of the real flow parallel to the principal axis without some error.*

If more than one meter is used, the correct velocity components can still be found for some cases. Specifically, one possible case is where two-dimensional flow is present in the plane formed by the axes of two orthogonal meters. The details, however, will not be given here since the more important case is where three-dimensional flow is present. Using three or more meters with noncosine responses does not appear to be feasible.

The present need is to determine the seriousness of a noncosine response and to investigate the improvement of response characteristics.

*Lane 10 states, for a meter of similar design, ". . the proper component of flow along the axis of the instrument is recorded." (Result of tow tank tests at constant speed.) However, no data were given and figure 7 will be assumed to be more typical for this kind of meter. 


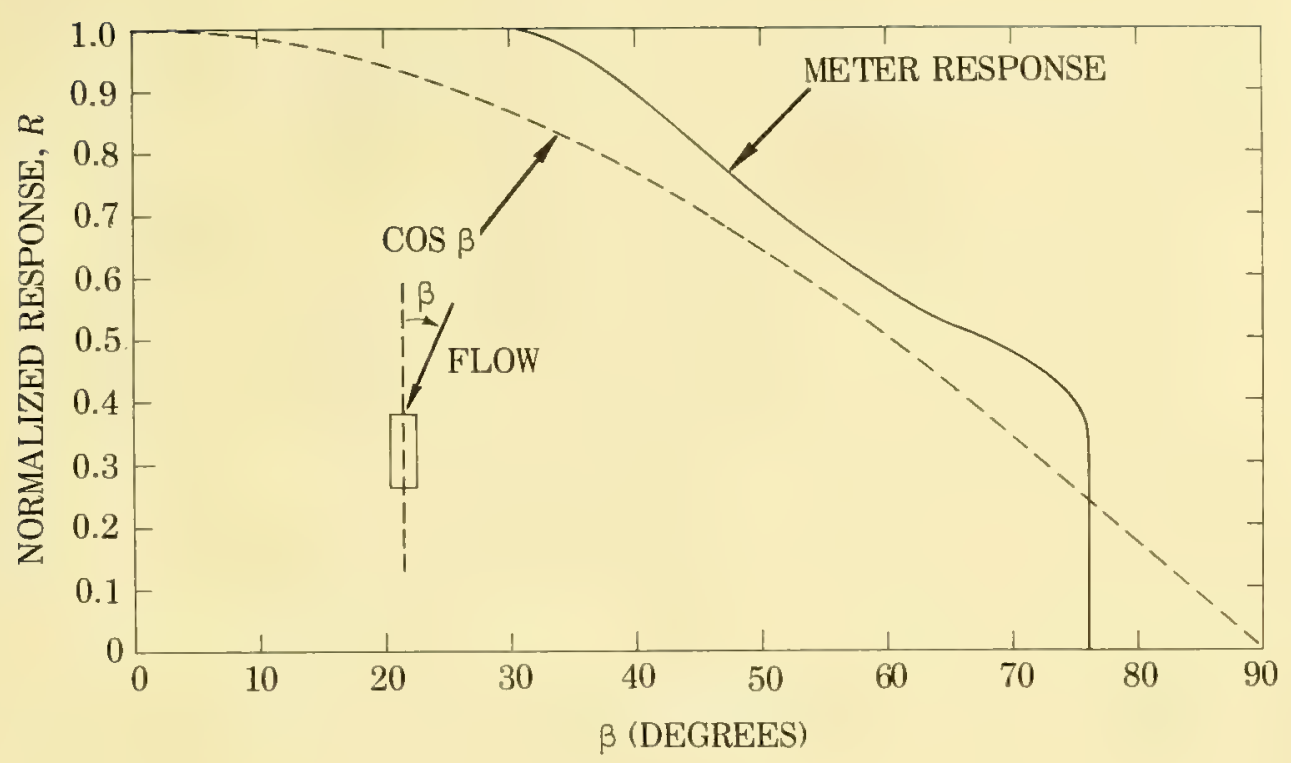

Figure 7. Directional response of Marine Advisers Inc. ducted current meter Q-8 (data taken from Marine Advisers polar plot, operating instructions manual).

\section{SUMMARY}

The use of impellor meters for shallow-water oceanographic measurements is not recommended. Nonlinear outputs give rise to false dc levels when filtered. Threshold and calibration changes at low velocities, caused by fouling, would probably be serious, and the noncosine response is a disadvantage. The use of two or three meters in the impellor system would result in hydrodynamic interference between the meters.

\section{Electromagnetic}

Electromagnetic flowmeters, or induction meters, have been towed from ships for oceanographic measurements or used to measure flow in channels. ${ }^{11}$ One possible oceanographic application concerns the flow in tubes with artificially generated magnetic fields, where the tube gives the meter some directionality. A typical transverse magnetic-field configuration is shown in figure 8. Electrodes are mounted flush with the inside of the pipe wall and are in contact with the fluid. The line joining the electrodes is perpendicular both to the magnetic field and the flow. Magnetic fields may be ac or dc, although with electrolytic solutions such as sea water, ac fields reduce electrode polarization.

Analytical work with these meters assumes that the fluid is nonmagnetic with the same permeability as a vacuum; conductivity of fluid, $\sigma$, is assumed isotropic. The Hall effect is neglected, and variations in conductivity and thermoelectric effects are assumed negligible. The conductivity of the pipe walls 
is assumed to be low compared with that of the fluid. Variations of electrical conductivity can generally be neglected if the impedance of the measuring instrument is high compared with the internal impedance of the meter.

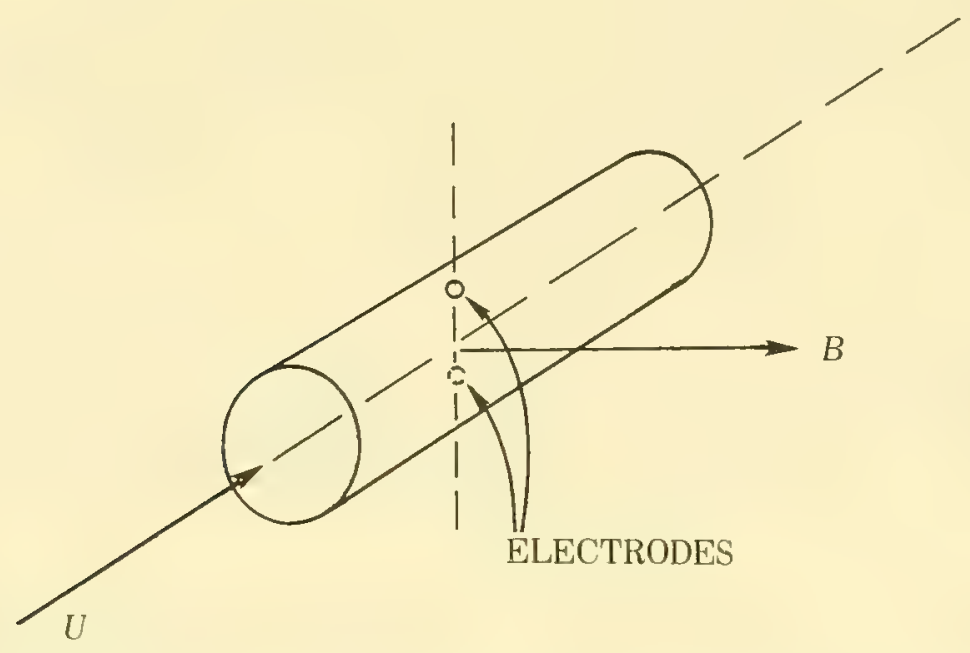

Figure 8. Transverse magnetic field configuration, electromagnetic flowmeter.

\section{DESIGN PARAMETERS}

The most important design parameters include choice of ac magnetic field frequency; length and diameter of pipe; choice of materials; effects of meter length on magnetic field uniformity; methods of reducing and compensating unwanted ac pickup, and use of electrodes or coils for measuring induced voltage. One meter used in oceanography has a faired housing around the tube.

\section{ADVANTAGES}

The induction flowmeter used no moving or intricate parts. The method is inherently capable of measuring direction as well as magnitude of flow. Linearity is good; errors of less than one percent appear possible with careful design and proper use. The output is independent of the conductivity of the fluid if the measuring instrument impedance is high compared with the internal impedance of the meter. The output is therefore practically independent of changes in temperature, pressure, and density of the liquid. Without moving parts, upper frequency limits are high and the device can measure turbulent flow. In circular transverse field meters, concentric deposits of solid matter on the pipe walls, if they have the same conductivity as the fluid, do not change the calibration. ${ }^{11}$ The simple mechanical design allows for easy cleaning. 
The induced voltage is usually independent of the electrical properties of the fluid. However, this is not true for all designs or conductivities. 12 If the meter requires salt water (conductivity, $\sigma=4 \mathrm{mho} / \mathrm{m}$ ) for accurate calibration instead of fresh water (tap water $\sigma=10^{-2} \mathrm{mho} / \mathrm{m}$ ), the choice of tow tanks is severely limited. Two or three orthogonally mounted meters might interfere hydrodynamically with the flow, depending on the size and shape of the sensors and on the distance between the electronics package and the sensors.

\section{DIRECTIONALITY}

A serious problem results from the use of the tube to obtain directionality. The direction response is unlikely to be a cosine function for two reasons:

1. As the meter is turned through an angle $\Theta$ with reference to the flow, the mean volumetric flow will probably not be proportional to $\cos \Theta$ for hydrodynamic reasons.

2. As the meter is turned through the angle $\Theta$, the velocity distribution no longer remains symmetrical about the meter axis.

Thürlemann (results summarized by Shercliff ${ }^{11}$ ) proved that in a transversefield flowmeter with circular cross section, the voltage induced in the electrodes is proportional to the mean volumetric rate of flow so long as the velocity distribution is symmetrical about the axis of the tube. Serious errors can result from flows with asymmetrical velocity distributions. ${ }^{8}$ Failure to produce a cosine response would lead to the same problems in resolving the instantaneous magnitude and angle of the three-dimensional vector as was found with the ducted impellor meters.

NONCOSINE DIRECTION RESPONSE. A noncosine direction response can represent a serious problem. Since instantaneous velocity is not required for this application, the question is posed as to whether the filtered output will indicate the steady flow correctly when given both an oscillating and.steady flow. The noncosine response will be assumed to be the only fault of the meter. The meter will be considered perfect in other respects: linear output, perfect frequency response; and no zero drift. The ability to sense flow direction will be assumed. Let the meter be placed at a given depth with its axis parallel to the $y$-axis (fig. 9). A typical flow direction would be as follows:

Let $U$ be the instantaneous resultant flow at angle $\beta$ to the $y$ axis. The velocity components $U_{x}, U_{y}, U_{z}$, and $U_{r}$ are shown. Let plane surface waves be traveling in a direction parallel to the $U_{T}$ component and give rise to the oscillating 


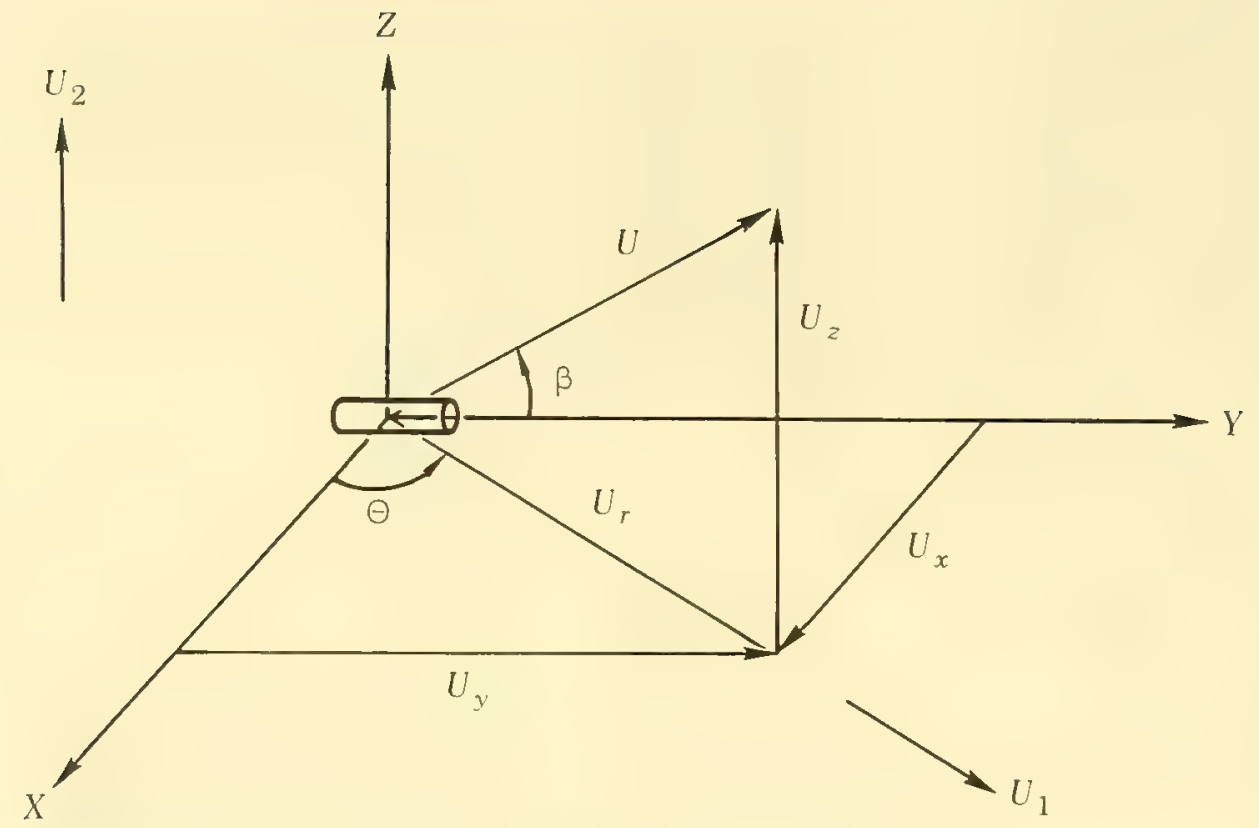

Figure 9. Noncosine directional response, linear output example.

part of the flow at the meter depth. Circular orbital velocities will be assumed. The flow components, including the steady-state values, will be given by

$$
\begin{aligned}
& U_{T}=U_{1}+U_{m} \cos \omega t \\
& U_{z}=U_{2}+U_{m} \sin \omega t
\end{aligned}
$$

where $U_{r}$ and $U_{z}$ are the flow components shown,

$$
\begin{aligned}
& U_{1}=\text { steady-state flow component parallel to } U_{r} \\
& U_{2}=\text { steady-state flow component in the positive } z \text { direction } \\
& U_{m}=\text { amplitude of the oscillating flow }
\end{aligned}
$$

The output of the meter at angle $\beta$ can be written as

$$
e=\left.e\right|_{\beta=0}(R)
$$

where

$$
\begin{aligned}
& \left.e\right|_{\beta=0}=\text { meter output at } \beta=0 \\
& R=\text { meter response at } \beta \\
& 0 \leq R \leq 1
\end{aligned}
$$


Now since the output was assumed linear, equation (10) can be written

$$
e=K U R
$$

where

$$
\begin{aligned}
& K=\text { constant } \\
& K>0 .
\end{aligned}
$$

The mean (or filtered) value over one wave cycle, $\bar{e}$, can be found from

$$
\bar{e}=\frac{K}{2 \pi} \int_{0}^{2 \pi} U R d(\omega t) \text { where }|U|=\left(U_{z}^{2}+U_{r}^{2}\right)^{1 / 2}
$$

The value of $R$ is a known empirical function of $\beta$. The value of $\beta$ is given by

$$
\beta=\cos ^{-1}\left(\frac{U_{y}}{|U|}\right) \text { where } U_{y}=U_{r} \sin \Theta
$$

Using this value for $U_{y}$, equation (8) for $U_{r}$, and equation (12) for $U$,

$$
\beta=\cos ^{-1}\left[\frac{\left(U_{1}+U_{m} \cos \omega t\right) \sin \Theta}{\left(U_{z}^{2}+U_{r}^{2}\right)^{1 / 2}}\right]
$$

As a check, let $R=\cos \beta$. Using equations (12) and (14), where $U_{1}, U_{m}$, and $\Theta$ are constants,

$$
\bar{e}=\frac{1}{2 \pi} \int_{0}^{2 \pi}\left(U_{\mathrm{z}}^{2}+U_{r}^{2}\right)^{1 / 2}\left[\frac{\left(U_{1}+U_{m} \cos \omega t\right) \sin \Theta}{\left(U_{z}^{2}+U_{r}^{2}\right)^{1 / 2}}\right] d \omega t=U_{1} \sin \Theta
$$

Thus the correct steady-state component along the meter axis is indicated when the response is a cosine function.

Equation (12) cannot be used at this time for an example of an electromagnetic meter since an actual direction response is not known. However, to illustrate the method, a direction response the same as the Marine Advisers Model Q-8 ducted meter (fig. 7) will be used. This was a noncosine response that would probably be somewhat typical for an electromagnetic meter. The function of $R$ vs $\beta$ (fig. 7) was approximated by a series of straight lines, connected by points taken at 5 -degree intervals. Linear interpolation was used between points. The discontinuity at $\beta=76$ degrees was avoided by letting $R=0.356$ at 
76 degrees and 0 at 77 degrees. In order to evaluate $\bar{e}$, using this actual table of $R$ vs $\beta$, equation (12) was modified for computer use as follows:

$$
\bar{e}=\frac{1}{N+1} \sum_{n=0}^{N} U R
$$

Substituting the value of $U$ from equation (12),

$$
\bar{e}=\frac{1}{N+1} \sum_{n=0}^{N} \pm\left(U_{z}^{2}+U_{r}^{2}\right)^{1 / 2}
$$

where

$$
\begin{aligned}
& U_{z}=U_{2}+U_{m} \sin (n \Delta) \\
& U_{r}=U_{1}+U_{m} \cos (n \Delta) \\
& R=\text { function of } \beta \text { from the table } \\
& \beta=\cos ^{-1}\left(\frac{U_{y}}{|U|}\right)=\cos ^{-1}\left(\frac{U_{r} \sin \Theta}{|U|}\right) \\
& \Theta=\text { positive constant }
\end{aligned}
$$

In equation (17), the positive sign is used if $U_{y}>0$ and the negative sign if $U_{y}<0$.

The value of $\bar{e}$ was computed for some typical values using $\Delta=0.1$ degree and $N=3600$. This is the actual mean output of the meter. The ideal mean output along the meter axis would simply be $U_{1} \sin \Theta$. The results are plotted in figure 10. The ratio of the actual mean output to the ideal mean output is used as the ordinate and $\Theta$ as the abscissa. The asymmetric nature of the input and the noncosine meter meter response cause the errors in the mean output in the figure to range from 9 to 23 percent. However, it should be noted from the curves that these errors are mainly a function of $\Theta$ and almost independent of $U_{1}$ and $U_{2}$. This suggests the possibility of correcting errors of this type. A more detailed analysis should be deferred until the exact nature of the response curve for an electromagnetic meter is determined. 


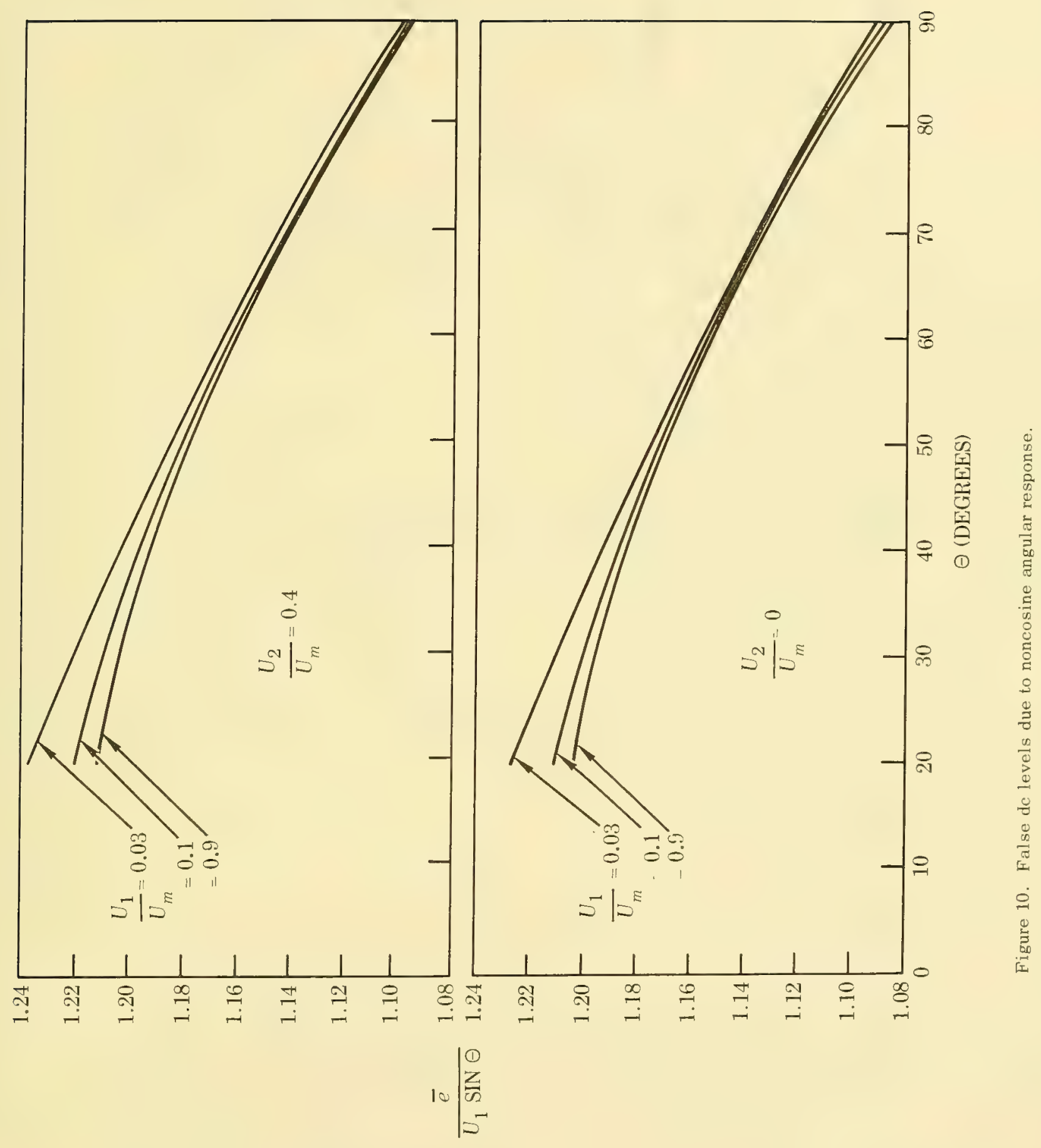


No tubes are used to obtain directionality in the method of induction-flow measurement that uses the earth's magnetic field. The induced voltages between electrodes can be given by

$$
V=U H L \times 10^{-8}
$$

where $U=$ fluid velocity (cm per second); $H$ = earth's magnetic field (gauss); $L=$ distance between electrodes $(\mathrm{cm}) ; V=$ induced voltage (volts); and where $U, H$, and the line joining the electrodes are mutually perpendicular.

The low strength of the earth's field causes the signals to be very small. Large separation of electrodes thus becomes necessary to obtain reasonable voltage levels. A typical signal for electrodes of 100 -meter separation is 2.5 millivolts per knot. Since the earth's field is stationary, the de voltages induced cause some polarization problems.

Modern electrometers with very high input resistance are available to minimize loading problems. Calibration and testing in a tow tank is impossible for electrode spacings of this size. Location has to be distant from large bodies of iron such as tower structures or ships. Effects from the sea floor must be considered. Generally the velocity measured will be that component which is perpendicular to the line joining the electrodes and to the magnetic field. In practice, the line joining the electrodes can be placed parallel to the horizontal component of the earth's field. Then only the vertical component of the earth's field will produce an output. The output will be proportional to only the horizontalvelocity component perpendicular to the line joining the electrodes. Other orientations may produce signals due to vertical as well as horizontal-velocity components. The method is inherently capable of sensing direction of flow. The output polarity at the electrodes is merely reversed. Zero drifts can be of the same order of magnitude as the signal and are inherently difficult to determine. One method for shunting the electrodes to obtain an electrical zero is given by Mangelsdorf. ${ }^{13}$

\section{MEASUREMENT OF VELOCITIES}

The measurement of velocities over large distances ( 100 meters) has a possibility for increasing signal-to-noise ratios. Assume the surface swell consists of plane waves of wavelength $\lambda$. Let an instrument measure horizontal-flow components in a direction parallel to the surface wave propagation. Measure this flow over a distance of $\lambda$ or integral multiples thereof. Thus a rejection filter results for the major source of noise, the swell of wavelength $\lambda$. The filtering is accomplished in the transducer itself and the method becomes Approach 3 (page 6 ). Typical values of $\lambda$ would be over 100 meters. In practice, both the direction and wavelength will change with time. Instrument placement would be determined by the expected swell direction and wavelength. 
It does not appear possible to place electrodes using the earth's field to produce such a rejection filter. Perhaps another configuration employing ac fields could be constructed to give average velocity readings over large distances.

The main advantages of the induction method are the lack of moving parts; high-frequency response; linear output; and direction-sensing ability. The major disadvantage with the tube-type meter using its own ac magnetic field is a probable noncosine direction response. The principal disadvantages with the earth's field method are the low signal levels and zeroing problems. Installation and proper maintenance would also be a problem. Direction response is a cosine function, and the rejection-filter configuration should be kept in mind.

\section{Drag Force}

\section{STEADY-STATE FLOW}

This method consists of recording the hydrodynamic drag on a fixed object, which for convenience is usually attached to a stiff suspension system. The small relative motion between the object and the mounting can be measured and recorded. The shape and size of the object and the suspension are design variables. given by

For the steady-state flow in the region of interest here, the drag can be

$$
D=1 / 2\left(C_{D} A \rho U|U|\right)
$$

where

$$
\begin{aligned}
& D=\text { drag force } \\
& C_{D}=\text { drag coefficient } \\
& A=\text { cross-sectional area of object perpendicular to flow } \\
& P=\text { fluid density } \\
& U=\text { velocity of object relative to fluid }
\end{aligned}
$$

The steady-state drag coefficient $C_{D}$ for a given shape is determined experimentally as a function of the nondimensional Reynolds number. The Reynolds number, $R$, is given by

$$
R=\frac{\rho U d}{\mu}=\frac{U d}{v}
$$


where

$$
\begin{aligned}
& U=\text { velocity of fluid relative to object } \\
& d=\text { characteristic dimension of object } \\
& \mu=\text { dynamic viscosity } \\
& \nu=\text { kinematic viscosity } \\
& \rho=\text { fluid density }
\end{aligned}
$$

As the Reynolds number increases, vortexes are produced and shed behind blunt bodies such as cylinders. When $R$ is between 10 and 40 , stationary vortexes are formed. Stable and well-defined vortex patterns are carried away or shed for $R$ between 40 and 150. The line of separation moves back and forth, and transverse forces appear which change direction with time. Using the Strouhal number, which is nondimensional and determined experimentally, the frequency can be found by the formula ${ }^{14}$

$$
f=\frac{S U}{d}
$$

where

$$
\begin{aligned}
& d=\text { diameter of body } \\
& f=\text { frequency of oscillation } \\
& U=\text { velocity } \\
& S=\text { Strouhal number }
\end{aligned}
$$

As $R$ is increased from 150 to $10^{4}$, the shedding becomes irregular.

\section{SHALLOW-WATER APPLICATION}

Considered so far have been objects in a steady-fluid flow, or objects moving at fixed velocities through a still fluid, after equilibrium has been reached. In the shallow-water case, however, oscillating flows are present because of wave action. This motion means that fluid acceleration is present which also influences the coefficient of drag, ${ }^{15-17}$ the wake formation, 18 and the apparent mass increase, which is called virtual, or added mass. ${ }^{19-22}$

Of prime importance are the variations in drag coefficient and mass coefficient with fluid acceleration. This problem has been studied theoretically and experimentally for unidirectional accelerated motions, arbitrary motions, and sinusoidal oscillations. Keulegan and Carpenter ${ }^{15}$ give a good review of these references, and present results of sinusoidal fluid oscillations for cylinders and 
plates. Their work is a good reference because it shows a systematic correlation of the variation in the coefficients of drag $\left(C_{D}\right)$ and mass $\left(C_{M}\right)$. The following items are described: analysis of forces on objects at rest in a moving fluid, with the special case of a cylinder in a sinusoidal fluid velocity; the experimental wave tank and force dynamometer; data reduction; flow patterns which resulted; and possible reasons for the variation in coefficients due to vortex formation. The results of primary interest were for cylinders:

1. The average values of $C_{D}$ and $C_{M}$ during a wave cycle were correlated with the period parameter $\frac{U_{m} T}{d}$ where $U_{m}$ is the amplitude of the sinusoidal fluid velocity. $T$ = period, $d=$ cylinder diameter. No correlation was found with the Reynolds number. The results are plotted in figures 11 and 12 .
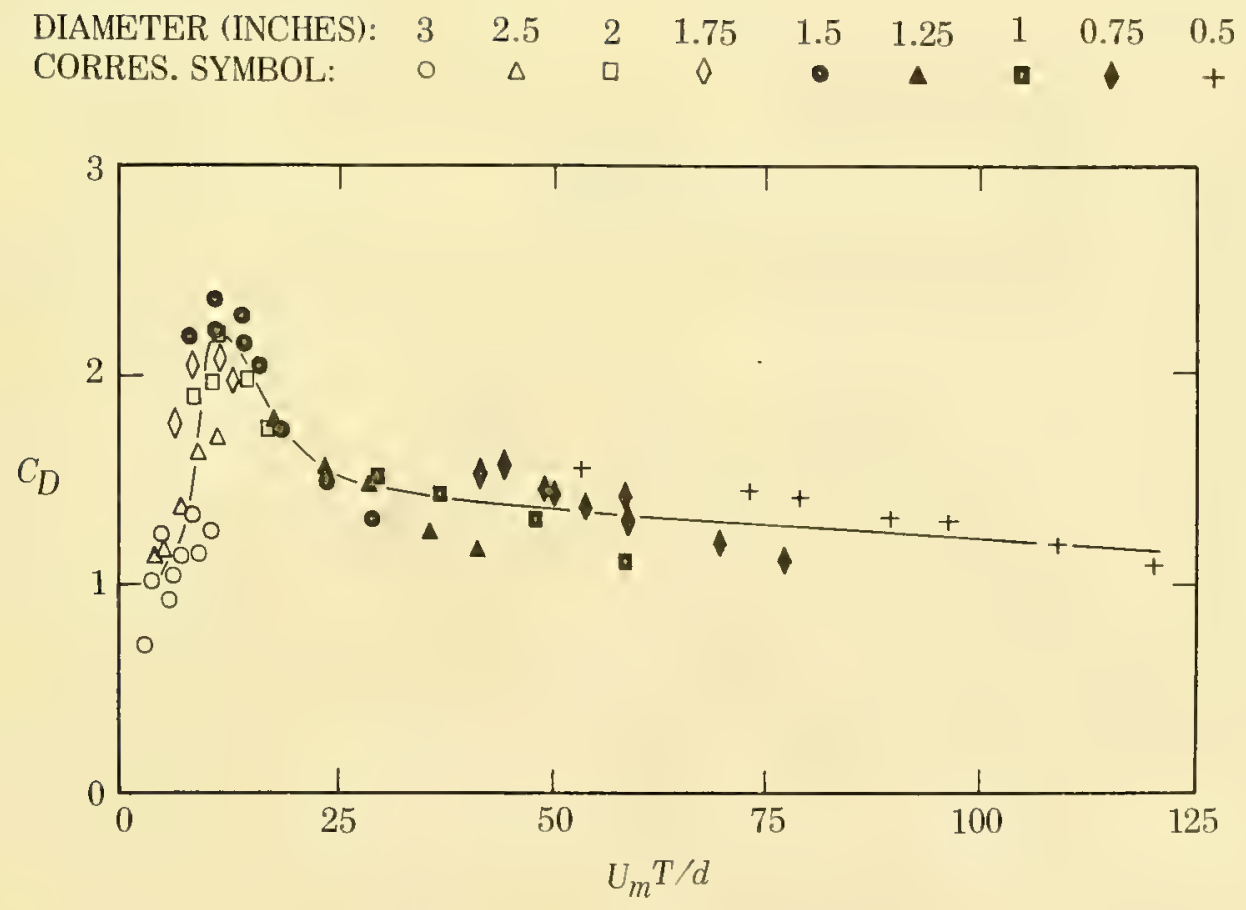

Figure 11. Variation of drag coefficient of cylinders. 15 


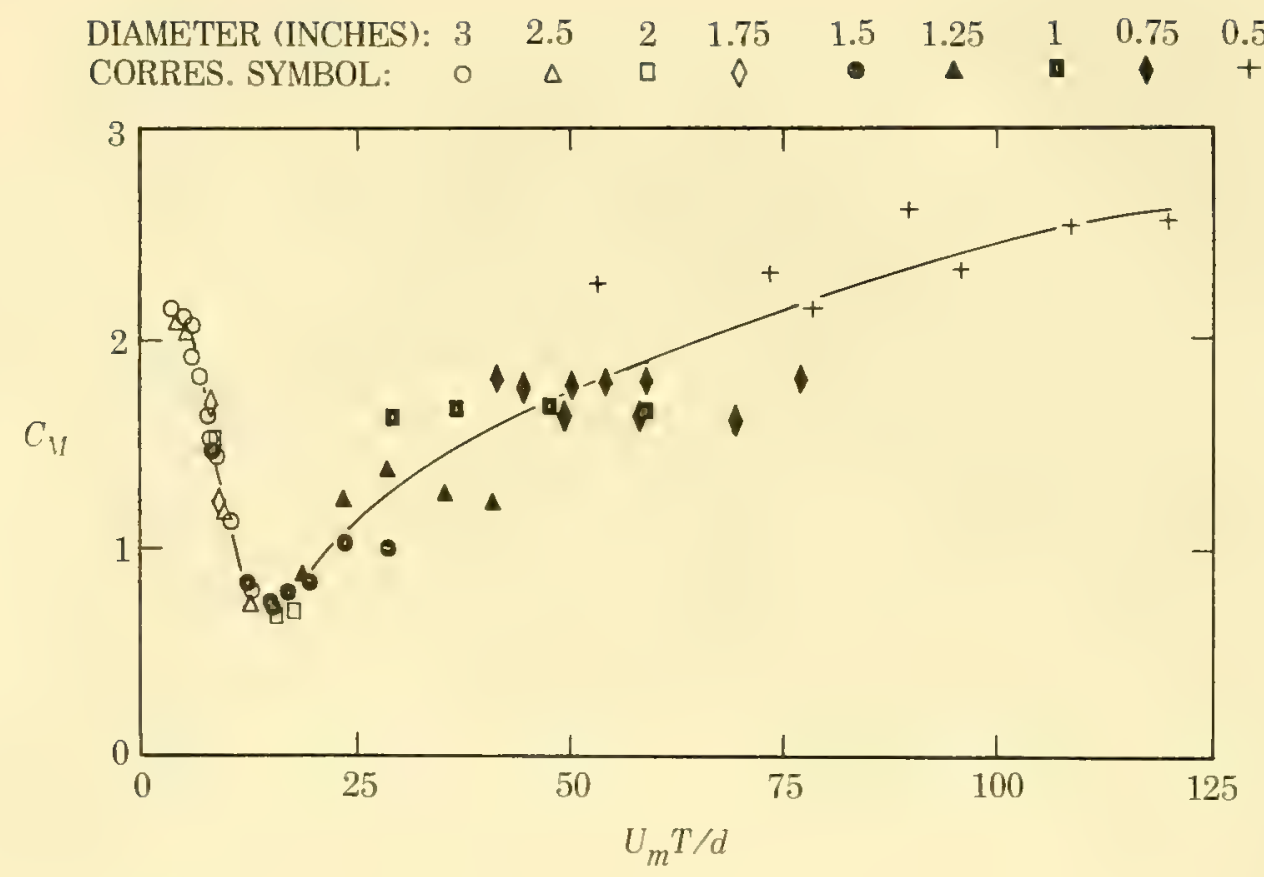

Figure 12. Variation of inertia coefficient of cylinders. 15

2. The variation of $C_{M}$ and $C_{D}$ throughout a given wave cycle were experimentally determined for use in the following equation:

$$
F=C_{M} \rho A_{O} \frac{d U}{d T}+1 / 2\left(C_{D} d \rho U|U|\right)
$$

where

$$
\begin{aligned}
& F=\text { force per unit length in direction of flow } \\
& C_{M}=\text { coefficient of mass } \\
& P \quad=\text { fluid density } \\
& A_{0}=\frac{\pi d^{2}}{4} \text { where } d \text { = diameter of object } \\
& U=\text { undisturbed fluid velocity } \\
& C_{D}=\text { drag coefficient }
\end{aligned}
$$

See results in figures 13,14 , and 15 for different values of period parameter. 


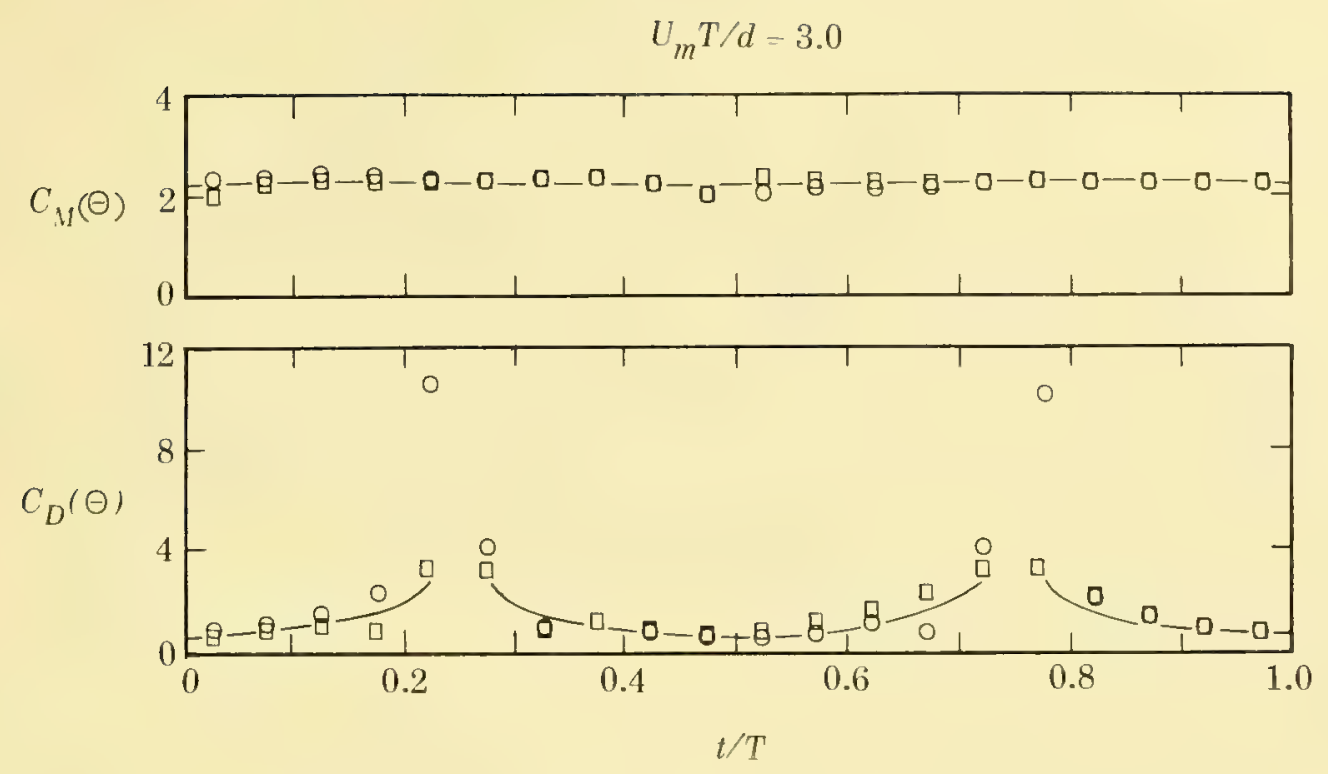

Figure 13. Example of variation of the inertia and drag coefficients of a cylinder during a wave cycle. 15

$$
U_{m} T / d=15.6
$$
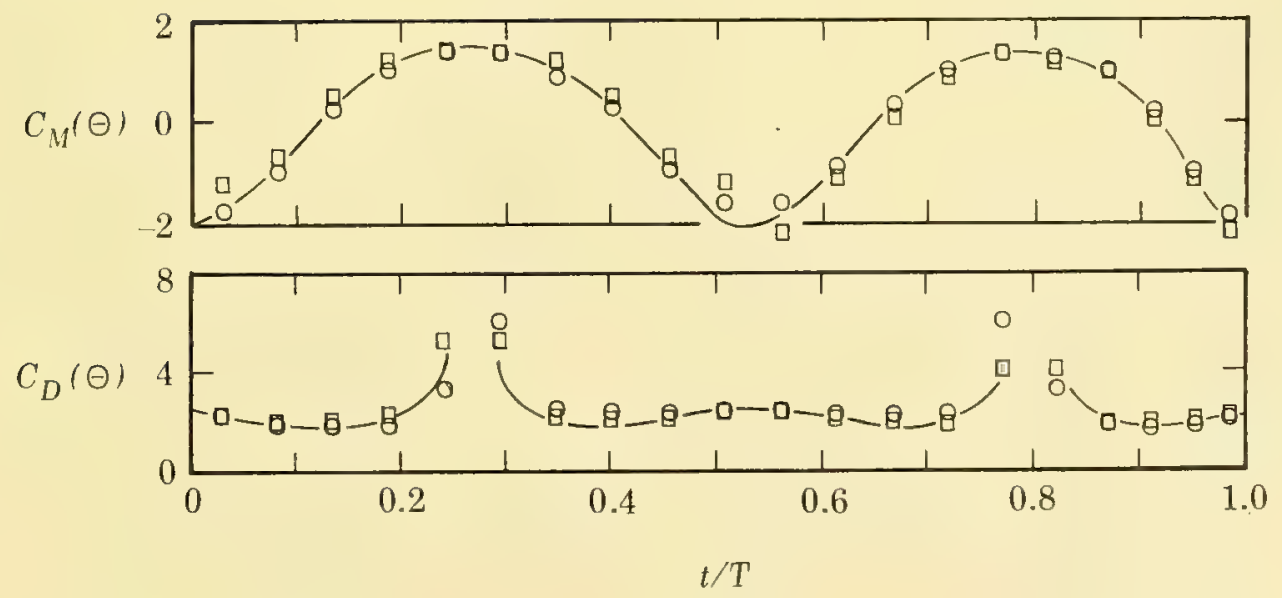

Figure 14. Example of variation of the inertia and drag coefficients of a cylinder during a wave cycle. 15 


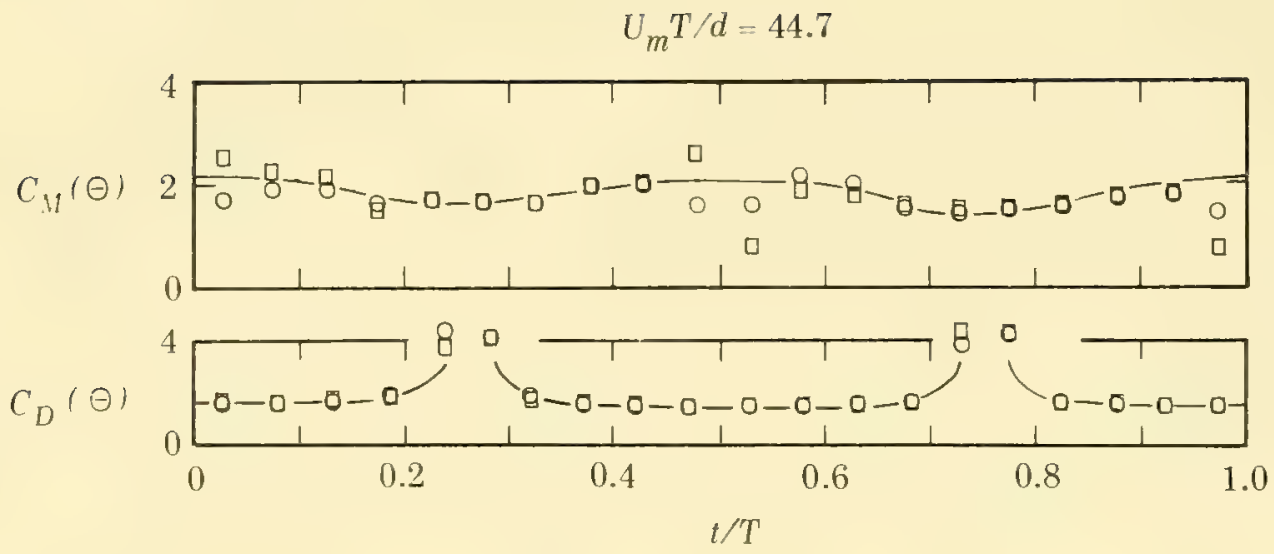

Figure 15. Example of variation of the inertia and drag coefficients of a cylinder during a wave cycle 15

3. The maximum force and phase were found as a function of period parameters (fig. 16).

The problem with using equation (24) for an actual current meter is that both $U$ and $\frac{d L^{\prime}}{d l}$ are unknown. It is therefore highly desirable for the parameters to be chosen so that the acceleration term can be neglected. Furthermore the value of $C_{D}$ should be constant over the operating range of the instrument. Corrections for variations of $C_{D}$ would be unrepeatable since these variations are connected with fluid acceleration and eddy formations, and varying coefficients complicate data reduction. Steady-state data show that the range of Reynolds number for constant $C_{D}$ is between $1 \times 10^{4}$ and $2 \times 10^{5}$. Figure 11 shows that the higher values of the period parameter $\left(\frac{U_{m} T}{d}\right)$ are desired because $C_{D}$ and $C_{M}$ are nearly constant in this range. In the shallow ocean, $U_{m}$ and $T$ are fixed by the amplitude and period of the swell. The only variable over which there is control is the diameter $d$ of the cylinder, which must be small if period parameters are to be large. The reduction of $d$, however, reduces the drag force proportionately. These smaller forces produce more demands on the electrical transducer. 


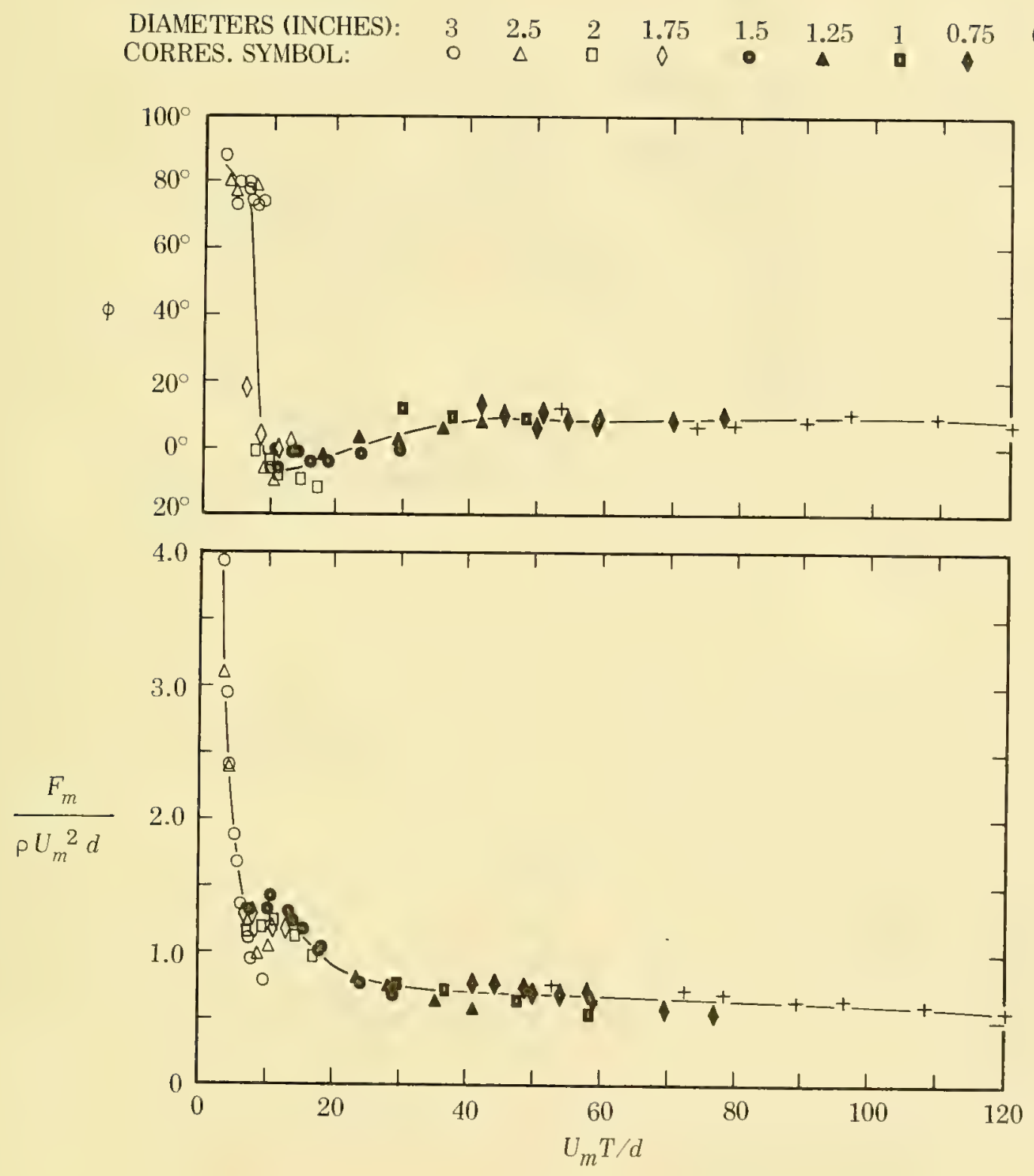

Figure 16. Variations of the magnitude and phase of the maximum force on cylinders. 15 
An actual meter of this type (fig. 17) was constructed in order to learn more about the range of variables to be encountered. Data samples (figs. 18 and 19) were taken at the NEL Oceanographic Research Tower ${ }^{23}$ where the water depth is 60 feet. Both records were taken at a depth of 40 feet; one shows the north-south component and the other the east-west component. These records will serve as examples of typical parameters that influence the accuracy of the method. Keulegan's results can then be applied.

A cylindrically shaped object attached to a cantilevered beam (fig. 20) was used. The beam shape causes the cylinder to bend in only one plane and therefore the meter is directional. The bending is measured by strain gages cemented to each side of the beam. The hydrodynamic drag on the cylinder causes the beam to bend and compress one strain gage and stretch the other. This produces an equal resistance change in the gages, which in turn produces a voltage output in a de Wheatstone bridge circuit.

The problems with the instrument include how to make a sensitive electrical transducer with satisfactory, long-term stability and a low temperature coefficient while retaining rugged mechanical construction and a high natural frequency. However, consider now only the inherent hydrodynamic characteristics and assume that a perfect electrical transducer can be built. Its voltage output would be proportional to the drag force on the cylinder and would have perfect stability without temperature coefficient.

First the values of period parameter $\frac{U_{m} T}{d}$ are computed. The approximate range of period parameter during the 3 days when data were taken was 40 to 240 for the north-south direction and 60 to 410 for the east-west direction, with $d$ constant and equal to 0.51 centimeter. The ranges cover about 90 percent of the cases. A typical value for the period parameter was about 200 with $T=10$ seconds and $U_{m}=10$ centimeters per second.

The easiest and most accurate quantity to find is the maximum velocity during a wave cycle since at this point $\frac{d U}{d t}=0$. Figure 16, which shows the variation of the magnitude and phase of the maximum force as a function of period parameter, can be used. These curves assume a sinusoidal velocity variation. For example by using a typical value of 200 for the period parameter, $\frac{F_{m}}{\rho U_{m}^{2} d}$ approaches 0.6 . Therefore $F=0.6 \rho U_{m}^{2} d$, which is the same as using only the second term in equation (24) with a drag coefficient value of 1.2 . This is the steady-state drag coefficient value commonly used. Thus for high period parameter values, the acceleration term is relatively unimportant in finding maximum velocity. Note that the phase shift of the maximum force does not approach zero even for large-period parameter values.

Consider the case where it is desired to find the velocity throughout one wave cycle. As shown in figures 13 and 15, if the period parameter is either small (3) or large (44.7), the values of $C_{M}$ and $C_{D}$ are roughly constant over the entire cycle. The greatest variation of $C_{M}$ and $C_{D}$ is at $\frac{t}{T}=0.25$ and 0.75 . 


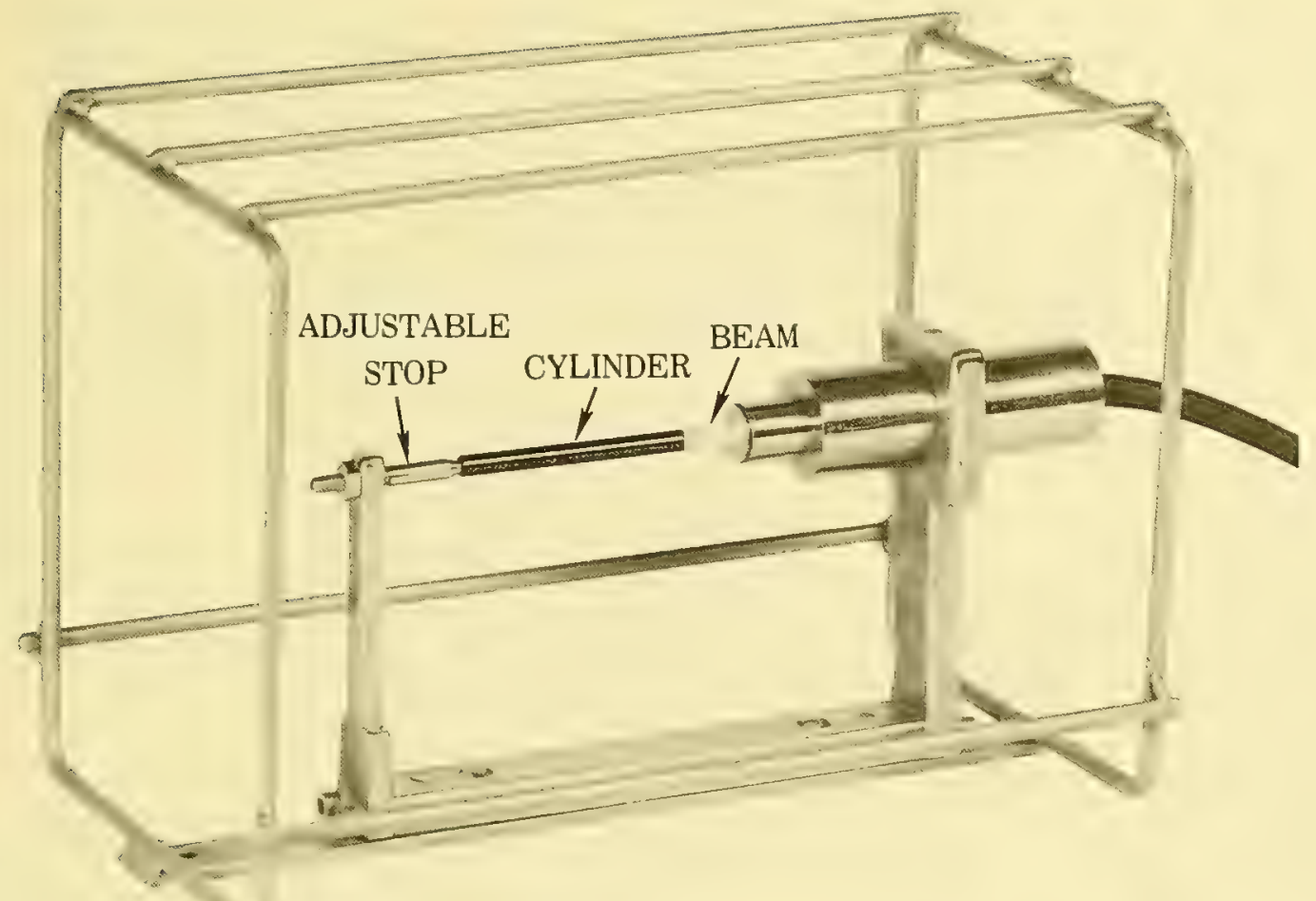

Figure 17. Drag force current meter.

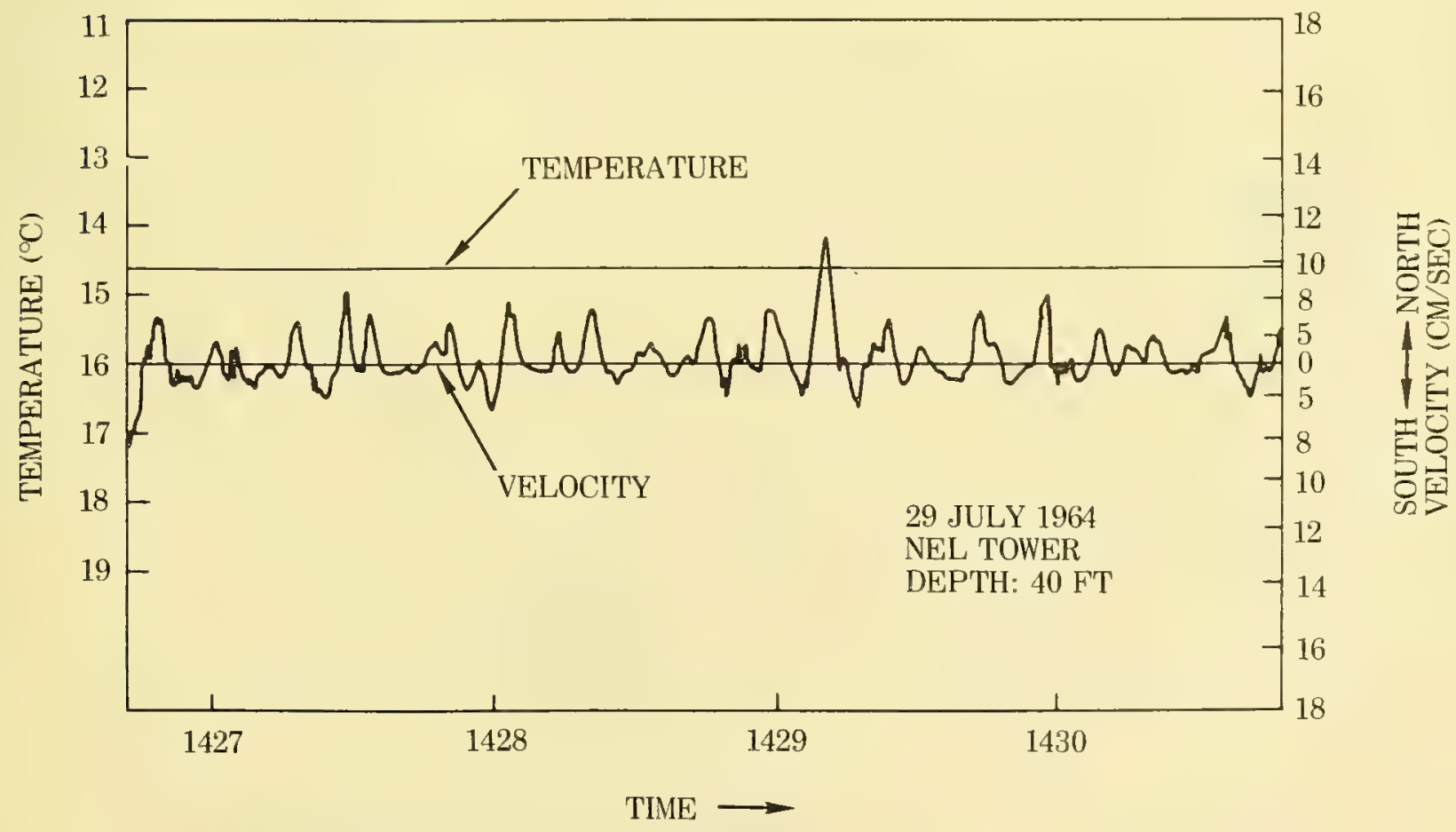

Figure 18. Recorder sample during run 2 (north-south). 


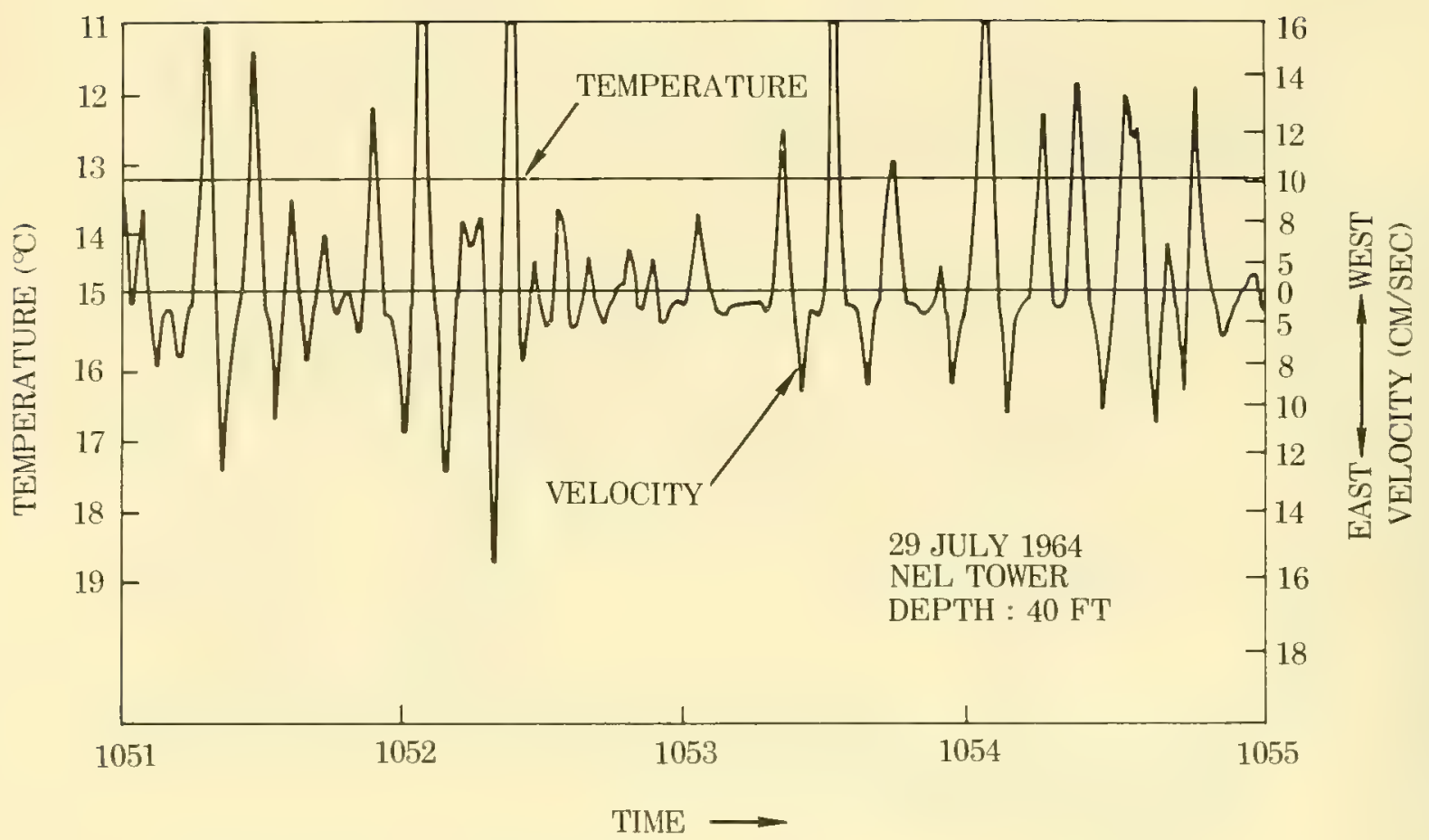

Figure 19. Recorder sample during run 1 (east-west).

TOP VIEW
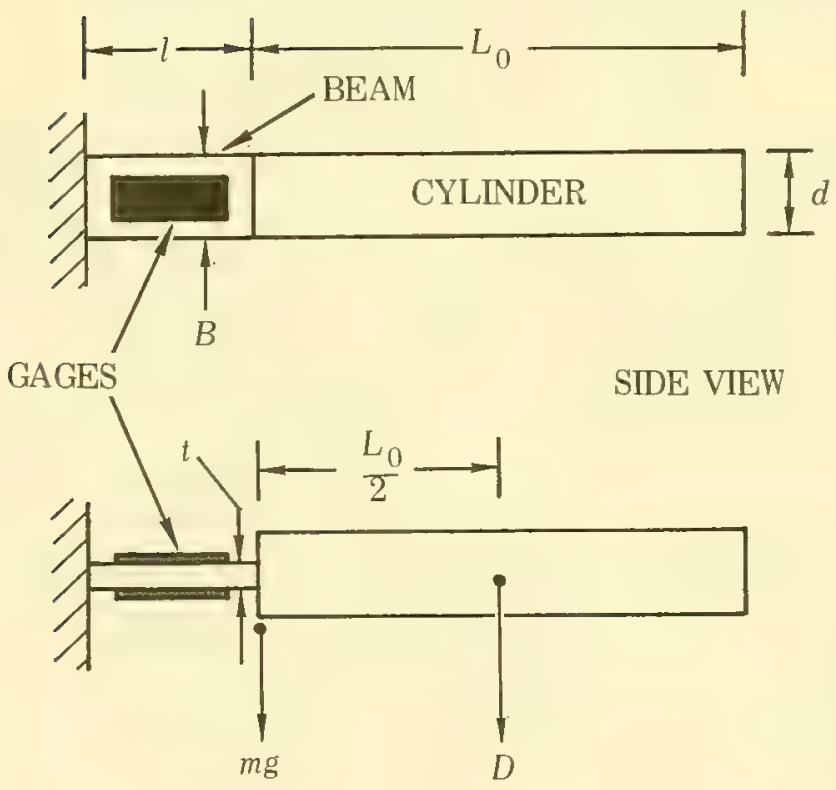

$$
\begin{aligned}
& B-d \quad 0.514 \mathrm{CM} \\
& L_{0}=5.76 \mathrm{CM} \\
& l=1.40 \mathrm{CM} \\
& t=0.057 \mathrm{CM}
\end{aligned}
$$

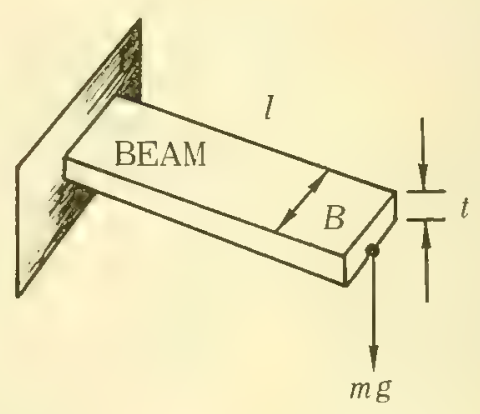

Figure 20: Schematic drawing of beam and cylinder 
These average values (for one cycle) can be found from figures 11 and 12 for use in equation (24).

In practice, both $U$ and $\frac{d u}{d t}$ are unknown, and knowing $C_{M}$ is of little use.

The errors in neglecting the acceleration term can be large, even at large values of period parameter. Take the typical case of $\frac{U_{m} T}{d} \cong 200, T=10$ seconds,

$U_{m}=10$ centimeters per second, $d=0.51$ centimeter. Extrapolating figures 11 and $12, C_{D} \cong 1.2$, and $C_{M} \cong 2.6$. Substituting these values into equation (24),

$$
F=0.54 \frac{d U}{d t}+0.31 U|U|
$$

Let $U=\sin \omega t$. Values of $F$ from the above equation are plotted in figure 21, first using only the velocity term and then using both terms. The force curve using both terms is what a real current meter would actually detect. Therefore by using this force curve and solving for $U$ in equation (24), where the acceleration term is neglected, the indicated velocity can be plotted (fig. 22). The true velocity, $U=\sin \omega t$, is also plotted for comparison. The large errors are obvious from the curves. Making $\frac{U_{m} T}{d}$ larger, by making $d$ smaller, probably will not change the values of $C_{1}$ and $C_{D}$. This is a reasonable assumption for $C_{D}$ until the critical Reynolds number is reached. The assumption for $C_{M}$ may not be valid although the curve in figure 12 appears asymptotic for large-period parameter values. The ratio of the velocity term to the acceleration term varies as $\frac{1}{d}$ in equation (24). By making $d$ smaller, the acceleration term could be made less significant. Making $d$ several times smaller, less than 0.51 centimeter, would reduce the forces to such a level that they would be hard to measure.

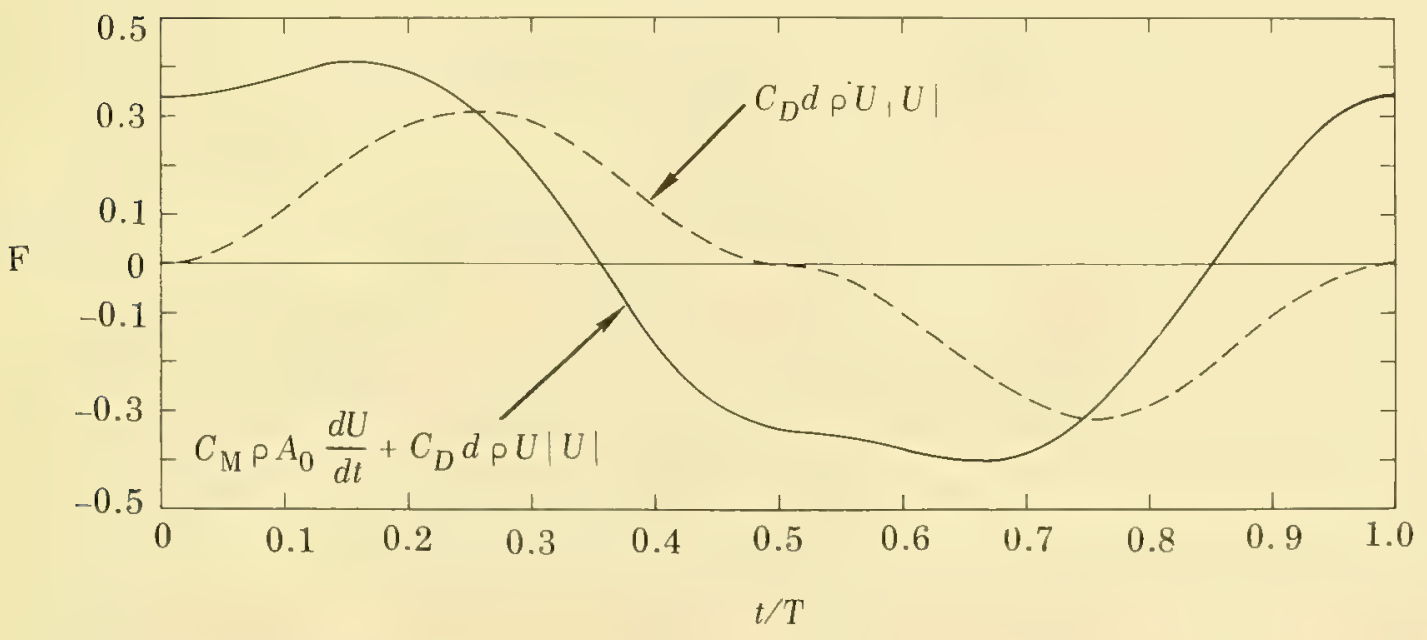

Figure 21. Drag force current meter example. 


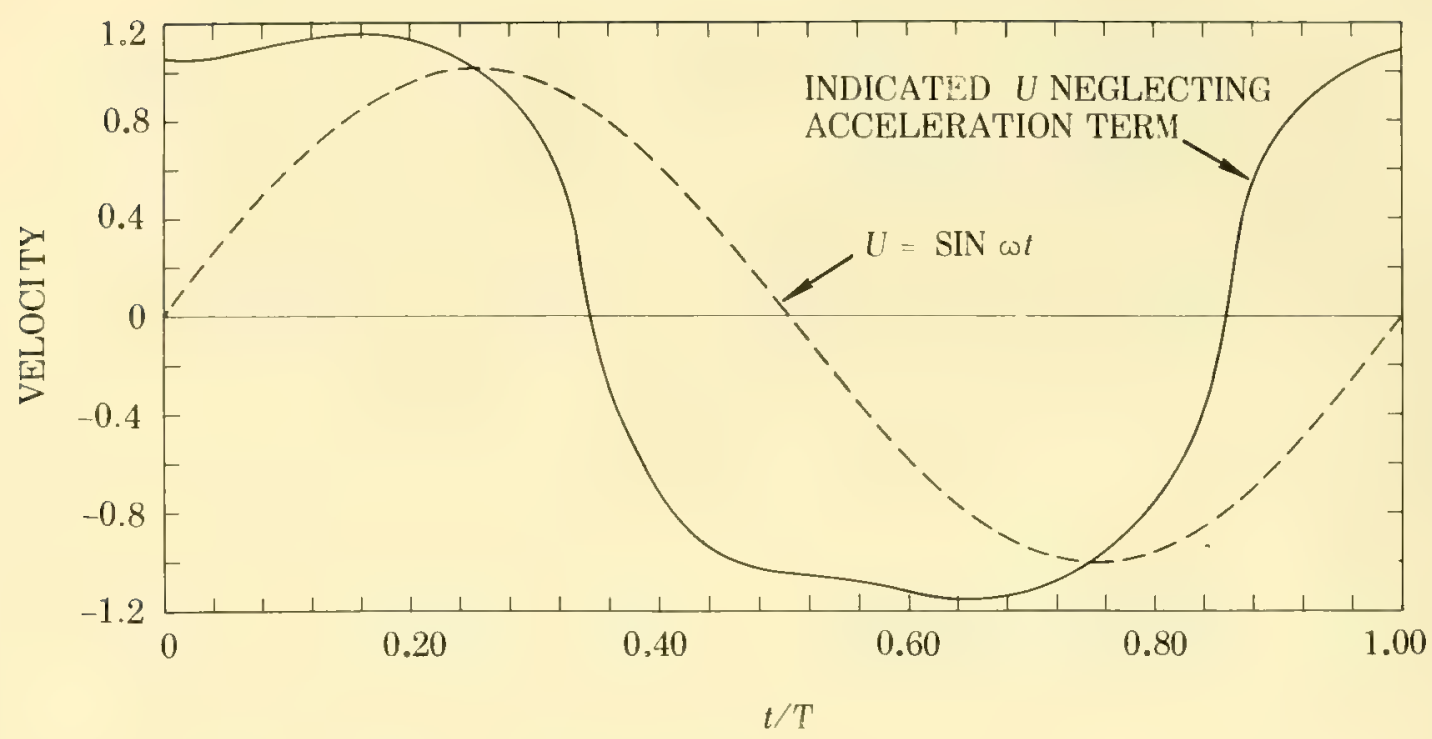

Figure 22. Drag force current meter example.

For values of period parameter near 15 (fig. 14), neither $C_{M}$ nor $C_{D}$ can really be considered constant throughout the wave cycle, and equation (24) cannot be used with constant coefficients. If data had period parameter values near 15, additional experimental work would be necessary.

An effort to recover any low-amplitude, low-frequency, or essentially dc signals in the presence of these typical swell records places very severe requirements on a system. No de velocity signals were ever detected visually on any of the Tower records.

\section{ACCURACY}

Consider now the accuracy of finding the steady $d-c$ velocity after filtering out the ac terms. For the first case, assume that high-period parameter values are used and therefore the drag coefficient will be constant throughout the wave cycle. If the inertial term in equation (24) could be neglected, the actual force per unit length on the cylinder, $F$, would be given by the second term of equation (24),

$$
F=K_{2} U|U|
$$

where

$$
K_{2}=1 / 2\left(C_{D} d p\right)=\text { constant }
$$


Let the actual velocity $U=U_{0}+U_{m} \sin \ominus$ where $U_{0}$ and $U_{m}$ are constants (fig. 23). Since the meter output, $e$, can be made linear with $F$,

$$
e=K_{2} K_{3} U|U|
$$

where

$$
K_{3}=\text { constant. }
$$

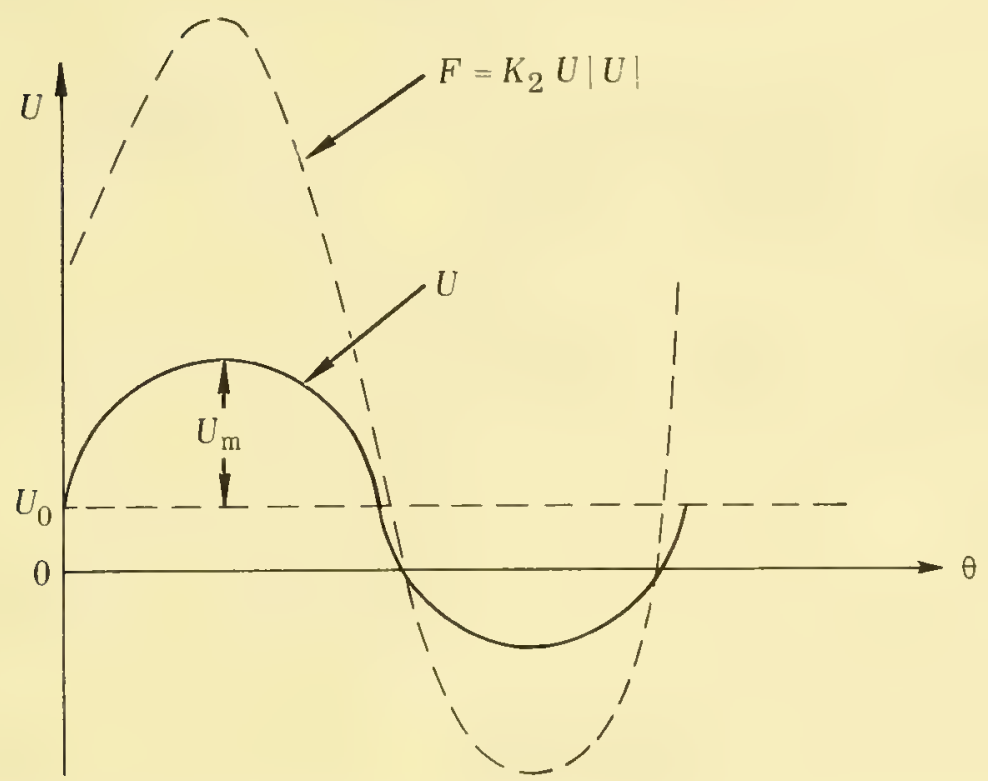

Figure 23. Ac + dc flow throughout one wave cycle where inertial term may be neglected and drag coefficient is constant; drag force current meter.

Now this actual output could be converted to the corresponding $U$ for every value of $\Theta$ before any filtering is done. Thus the indicated velocity, $U_{I}$, would simply be

$$
U_{I}= \pm\left|\frac{e}{\mathrm{~K}_{2} \mathrm{~K}_{3}}\right|^{1 / 2}= \pm U\left\{\begin{array}{l}
+ \text { if } U>0 \\
- \text { if } U<0
\end{array}\right.
$$

The mean value $\bar{U}_{I}$ over one wave cycle would then be

$$
\bar{U}_{I}=\frac{1}{2 \pi} \int_{0}^{2 \pi} U_{I} d \theta=U_{0}
$$

Therefore, for this case, the correct mean velocity $U_{0}$ would be found.

Next consider the case where the inertia term is still assumed negligible when solving for $\bar{U}_{I}$ (when in fact it is not). The drag coefficient is still 
considered constant. For this case the actual force must be given by both terms of equation (24),

$$
F-K_{1} \frac{d U}{d t}+K_{2} U(t
$$

where

$$
K_{1}=1 / 4\left(C_{M} p \pi d^{2}\right)=\text { constant }
$$

As before, let the true velocity be given by $U=U_{0}+U_{m} \sin \ominus$ and the actual output be linear with force.

Thus

$$
e=K_{1} K_{3} \frac{d U}{d t}+K_{2} K_{3} U \mid U
$$

Since the inertia term is still assumed negligible, equation (28) is again used to solve for the indicated velocity, resulting in

$$
U_{I}= \pm\left|\frac{1}{K_{2}}\left(K_{1} \frac{d U}{d t}+K_{2} U|U|\right)\right|^{1 / 2}
$$

And $\bar{U}_{I}$ can be found,

$$
\bar{U}_{I}=\frac{1}{2 \pi} \int_{0}^{2 \pi} U_{I} d \theta
$$

This method will not normally give the correct mean value $U_{0}$ when $U_{0} \neq 0$. As examples, values of $\bar{U}_{I}$ as found by numerical integration for two cases of $U_{0} / U_{m}$ are shown below.

The values of $K_{1}=0.54$ and $K_{2}=0.31$, obtained earlier for the typical example $U_{m}=10$ centimeters per second, $T=10$ seconds, $d=0.51$ centimeter, were used.

\begin{tabular}{c|c|c|c}
$U_{0}$ & $\begin{array}{c}U_{0}^{\prime} \\
(\mathrm{cm} / \mathrm{sec})\end{array}$ & $\begin{array}{c}\bar{U}_{I} \\
(\mathrm{~cm} / \mathrm{sec})\end{array}$ & $\begin{array}{c}\text { Percent Error } \\
\text { Between } \\
U_{0} \text { and } U_{I}\end{array}$ \\
\hline 0.2 & 2 & 1.7 & 15 \\
\hline 0.4 & 4 & 3.6 & 10
\end{tabular}


The indicated values of $\vec{U}_{I}$ were lower than the correct value $U_{0}$, and quite sizable errors resulted. The values through the wave cycle for the case where $U_{0} / U_{m}=0.2$ are plotted in figure 24 .

Other shapes can be used instead of cylinders; however, the same type of problem still exists. The inertial term cannot be neglected for flat plates except at very small values of period parameter. ${ }^{15}$ Adding to this is that quite large changes in $C_{D}$ and $C_{M}$ throughout the wave cycle exist for all values of period parameter. Although spheres were not studied, 15 the results would probably be similar to those with cylinders.

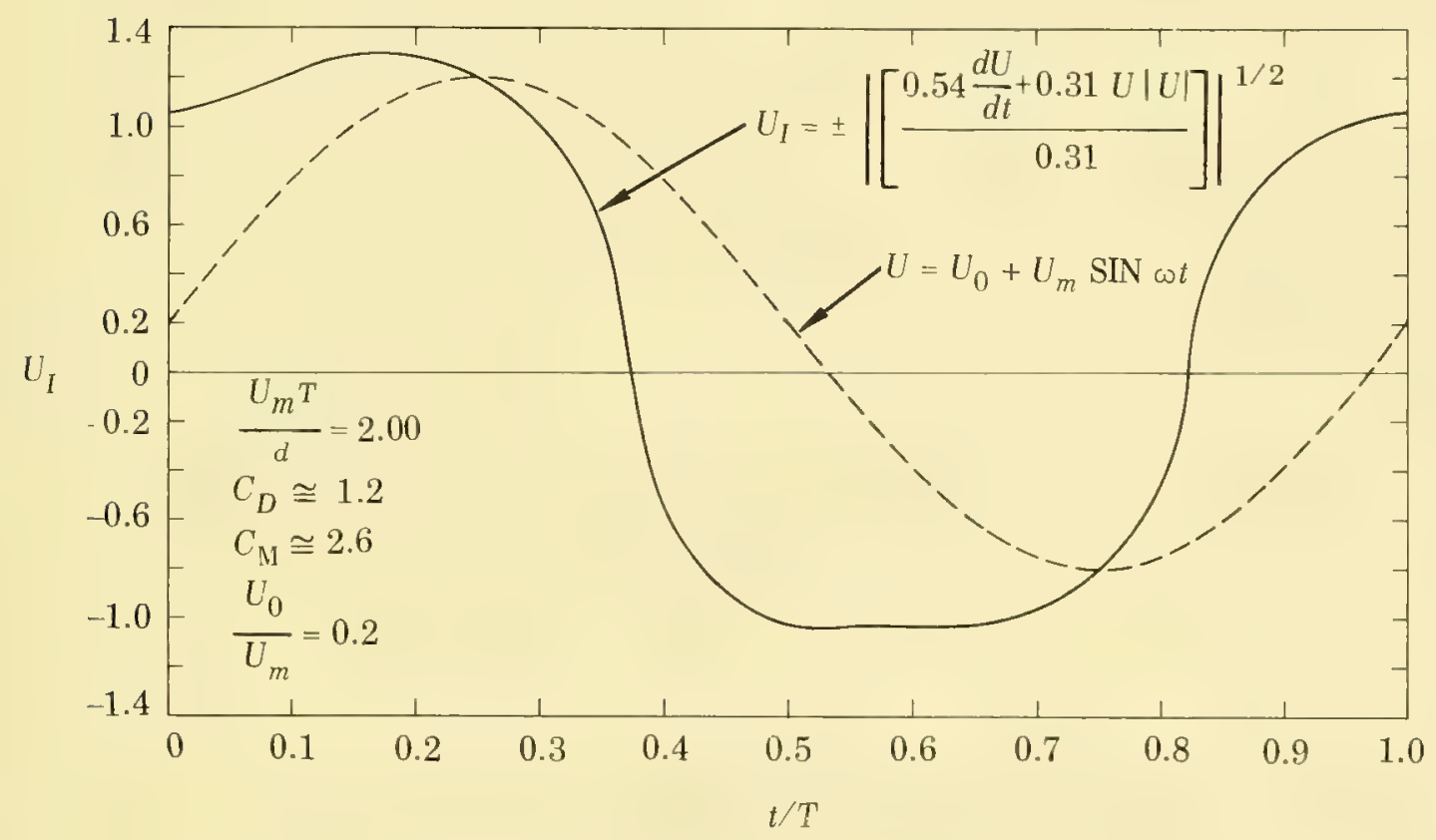

Figure 24. Drag force meter example.

\section{ADVANTAGES}

The good features of the drag force meter from a hydrodynamic standpoint are as follows:

1. The meter is small and has few moving parts.

2. The directional response can be made a cosine function.

3. The output will indicate both the magnitude and direction of a given velocity component. 
The bad features of the drag force meter from a hydrodynamic standpoint are as follows:

1. The meter has a nonlinear output, even in steady flow.

2. $C_{D}$ and $C_{M}$ vary for oscillating flows.

3. The values of $C_{M}$ are not small compared with the values of $C_{D}$ with $d U / d t$ unknown for data reduction use of inertia term. The neglect of this term may result in sizable errors in solving for the dc level.

4. The slope of the force (or output) vs velocity curve is zero at zero velocity, which makes the zero inherently difficult to determine accurately.

\section{SUMMARY}

The drag force method is not suitable for measuring low-level dc signals in the presence of these typical swell conditions. Even if a perfect electrical transducer could be built, the inherent hydrodynamic problems would be too great. This method is, however, being used successfully as a "surge recorder" where only the maximum value of the oscillating flow is required.

\section{LAGRANGIAN METHOD}

The Lagrangian Method involves determining the position of artificial tracers in space and time. Von Arx ${ }^{24}$ lists, as types of tracers, drift bottles, drift cards, radio buoys, contaminants such as dye or radioactive waste, current poles, deep drogues, neutrally buoyant floats, and ship drift. Current poles and "deep" drogues can be used in shallow water. Even though measurements are taken in shallow water, it is still desired to measure velocities at some predetermined depth. Near the surface, current poles could possibly be used whereas deep drogues would be needed for other depths. Current poles are basically long, thin, vertical spar buoys, with only a small portion above the water line, which are used for visual tracking. In the deep-drogue configuration, a surface float is connected to a submerged object having large drag by a fine line. The float is tracked visually.

Of the serious faults and disadvantages inherent in the Lagrangian Method when used in shallow water, the most obvious is the necessary support effort. Setting, tracking, and picking up drogues is by no means an easy task either at night or for long periods of time.

The output, which is a function of space and time, is not electrical and might not comply with the condition of a point measurement satisfactorily. Since 
the output is sampled, low-frequency aliasing must be kept in mind. Optical tracking consists of sampling positions, usually at equal time intervals.

The drogue, which must respond to the horizontal components of all velocities present, should either follow the de and ac velocities perfectly or act like a low-pass filter- have a reduced response to the ac flow, but follow the dc flow perfectly. However, the drogue would not normally follow the ac flow perfectly. A difference in velocity between the drogue and the ac flow will exist and vary with time. The drogue is a passive device that requires an external force obtained from this velocity difference in order to operate. The resulting force, however, on the drogue is not linear with velocity and can generate a false dc level except when the true de level is zero. With the fixed drag-force meters equipped with electrical readout, the nonlinear force vs velocity effect could in principle be taken out in the process of data reduction, but this is impossible with drogues.

Assume a velocity difference in the horizontal plane, $U$, between the drogue and the water given by $U=U_{0}+U_{m} \sin \Theta$, where $U_{0}$ and $U_{m}$ are constant. Assume that equation 24 can be used to describe the resulting force on the drogue. Assume $K_{1}$ and $K_{2}$ are constant throughout the wave cycle (this might not be a valid assumption in actual practice). Also assume that $U_{m}>U_{0}$. The net force per cycle, $\bar{F}$, can be found.

$$
\begin{aligned}
\bar{F} & =\frac{1}{2 \pi} \int_{0}^{2 \pi}\left(K_{1} \frac{d U}{d \Theta}+K_{2} U|U|\right) d \Theta \\
& =\frac{K_{2}}{2 \pi} \int_{0}^{2 \pi}\left(U_{0}+U_{m} \sin \Theta\right)\left|U_{0}+U_{m} \sin \Theta\right| d \Theta
\end{aligned}
$$

The mean value, $\bar{F}$, was evaluated numerically for one set of values. For a ratio of $U_{m} / U_{0}=5$, the net force per cycle, $\bar{F}$, was about 6.4 times larger than the ideal force which was found by using only $U_{0}$. False dc levels can thus be generated by filtered nonlinear ac terms and was in this case a function of $U_{m} / U_{0}$. This was only a crude example to show that the effect can occur. A more complete description would be quite complicated. Model studies would probably be necessary to show how serious the effect would be with real drogue configurations.

Another disadvantage appears with drogues constrained to stay at one preset depth. At any given time and at a constant depth, some horizontal velocity distribution exists. Assume that this is a sine wave. This sinusoidal spatial distribution travels through space as a function of time at the phase velocity, $c$, of the surface wave. Since the drogue is free to move only in the horizontal plane, the condition for the net horizontal force on the drogue to be minimum would exist only when the drogue is traveling at the velocity, $c$, also. This condition would be independent of the initial depth of the drogue as long as it stays at this depth. The use of drogues in shallow water is not recommended. 


\section{Short-Distance Tracers}

Normally the Lagrangian Method is used to describe the tracking of artificial tracers over relatively large distances (e.g. miles). However, several lowinertia tracer methods exist for shorter distances (e.g. less than one meter). Three methods are briefly listed:

1. Nuclear magnetic resonance. 25

2. Photographing the motion of small drops of colored liquid. ${ }^{26}$

3. Measure the temperature fluctuations in the wake of a sinusoidally heated fine wire. 27

These methods would be more suitable for laboratory or industrial application (e.g. pipe flow) than for oceanographic field work. Problems in the design of a three-dimensional ocean meter would be large and mainly practical in nature. These methods are not recommended at this time, but should be kept for possible future use.

\section{MISCELLANEOUS}

\section{Savonius Rotor Meters}

These should never be used in oscillating flow because of poor dynamic response $\mathrm{e}^{28}$ and rectifying action due to the omnidirectional response. 29

\section{Thermo-Anemometer Meters}

These types, such as the hot-wire anemometer, relate fluid velocity and the quantity of heat lost by a heated measuring element (thermistors, wires, films). They are inherently suited for high-frequency velocity fluctuations and not for applications requiring long-term stability. Changes in sensitivity due to fouling would probably be serious. Thermo-anemometer meters have no inherent capability for sensing direction and would require shrouds and/or multiple sensor arrays.

They are not recommended for the present application. 


\section{CONCLUSIONS}

1. The acoustic flowmeters, for several reasons, are not suitable for measurement of steady-state currents in shallow water.

2. The nonlinear outputs and the noncosine response of impellor flowmeters give rise to false dc levels when filtered.

3. The inherent hydrodynamic problems of the drag force method are too great.

4. The necessary support effort required for the Lagrangian method makes its employment impractical. Nonlinear forces produce false de levels.

5. The electromagnetic flowmeter is inherently capable of measuring direction of current; the output is linear. Direction response is unknown for the tube configuration.

\section{RECOMMENDATIONS}

The electromagnetic method is recommended for the intended use. Specific recommendations are as follows:

1. Investigate new configurations using ac fields that will provide minimum hydrodynamic interference and possibly measure flow over large distances.

2. AC Magnetic Field Tube Configuration (fig. 8): Experimentally determine the directional response of this type. Investigate effects of different length-to-diameter pipe ratios and pipe fairing shapes in order to obtain a nearly cosine response. By using the best response curve obtained, calculate the expected errors (similar to example on p. 25). Determine if these errors are acceptable.

3. Earth's Field Type: Use of this method is recommended only if a feature for zeroing the meter is employed (similar to description by Mangelsdorf ${ }^{13}$ ). 


\section{REFERENCES}

1. Blackman, R.B. and Tukey, J.W., The Measurement of Power Spectra, From the Point of View of Communications Engineering, p.28, 30, 55, Dover, 1958

2. Paquette, R.G. "Practical Problems in the Direct Measurement of Ocean Currents," p.135-146 in Symposium on Tranducers for Oceanic Research, San Diega, California, 1962. Proceedings, Plenum Press, 1963

3. Suellentrop, F.J. and others, "An Acoustic Ocean-Current Meter," p.190-193 in Marine Sciences Conference, Woods Hole, Massachusetts, 1961, A Collection of Instrumentation Papers Presented at the Marine Sciences Conference Held September 11-15, 1961 at Woods Hole, Massachusetts, Plenum Press, 1962

4. Lester, R.A., "High-Accuracy, Self-Calibrating Acoustic Fl ow Meters," p. 200-204 in Marine Sciences Conference, Woods Hole, Massachusetts, 1961, A Collection of Instrumentation Papers Presented at the Marine Sciences Conference Held September 11-15, 1961 at Woods Hole, Massachusetts, Plenum Press, 1962

5. Chalupnik, J.D. and Green, P.S., "A Doppler-Shift Ocean-Current Meter," p.194-199 in Marine Sciences Conference, Woods Hole, Massachusetts, 1961, A Collection of Instrumentation Papers Presented at the Marine Sciences Conference Held September 11-15, 1961 at Woods Hole, Massachusetts, Plenum Press, 1962

6. Koczy, F.F. and others, "A Doppler Current Meter," p.127-134 in Symposium on Tranducers for Oceanic Research, San Diego, California, 1962. Proceedings, Plenum Press, 1963

7. Grey, J., "Transient Response of the Turbine Flowmeter," Jet Propulsion, v.26, p.98-100, February 1956

8. Katys, G.P., Continuous Measurement of Unsteady Flow, p.143, Macmillan, 1964

9. Koppe, H., "Rotary Water Velocity Meter," Electrical Design News, v.9, p.50-51, June 1964

10. Yale University. Edwards Street Laboratory Contract NONR-609(02); Technical Report 40, Water Velocity Meter, by C.T. Lane, 27 January 1955

11. Shercliff, J.A., The Theory of Electromagnetic Flow-Measurement, p.109, 111, Cambridge University Press, 1962

12. Cushing, V., "Induction Flowmeter,' Review of Scientific Instruments, v.29, p.692-697, August 1958

13. Mangelsdorf, P.C., Jr., "The Worlds Longest Salt Bridge," p.173-185 in Marine Sciences Conference, Woods Hole, Massachusetts, 1961, A Collection of Instrumentation Papers Presented at the Marine Sciences Conference Held September 11-15, 1961 at Woods Hole, Massachusetts, Plenum Press, 1962 
14. Den Hartog, J.P., Mechanical Vibrations, McGraw-Hill, 1956

15. Keulegan, G.H. and Carpenter, L.H., "Forces on Cylinders and Plates in an Oscillating Fluid," Journal of Research of the National Bureau of Standards, v.60, p.423-440, May 1958

16. O'Brien, M.P. and Morison, J.R., "The Forces Exerted by Waves on Objects," American Geophysical Union. Transactions, v.33, p.32-38, February 1952

17. Hanson, A.R., "Piezoelectric Gauge For Measuring Cylinder Drag in a Fluctuating Air Stream," Review of Scientific Instruments, v.36, p.359-363, March 1965

18. Magarvey, R.H. and Blackford, B.L., "Wake Metamorphism Behind a Sphere," Canadian Journal of Physics, v.40, p.1036-1040, August 1962

19. Birkhoif, G., Hydrodynamics; A Study in Logic, Facts and Similitude, Revised ed., Princeion University Press, 1960

20. Iverson, H.W. and Balent, R., "A Correlating Modulus for Fluid Resistance in Accelerated Motion," Journal of Applied Physics, v.22, p.324-328, March 1951

21. Yu, Yee-Tak, "Virtual Masses and Moments of Inertia of Disks and Cylinders in Various Liquids," Journal of Applied Physics, v.13, p.66-69, January 1942

22. Underwater Sound Laboratory Technical Memorandum 933-351-64, Hydrodynamic Mass of Bodies in a Fluid, by K.T. Patton, 15 October 1964

23. Navy Electronics Laboratory Report 1342, The U.S. Navy Electronics Laboratory's Oceanographic Research Tower, by E.C. LaFond, 22 December 1965

24. von Arx, W.S., An Introduction to Physical Oceanography, p.223, AddisonWesley, 1962

25. Zhernovoi, A.I. and Latyshev, G.D., Nuclear Magnetic Resonance in a Flowing Liquid, Consultants Bureau, 1965

26. Columbia University. Lamont Geological Observatory Contract CU-4-62

Nonr 266(48)-Geology; Technical Report 4, A Suspended-Drop Current Meter, by E.M. Thorndike, March 1962

27. Walker, R.E. and Westenberg, A.A., "Absolute Low Speed Anemometer," Review of Scientific Instruments, v.27, p.844-848, October 1956

28. Gaul, R.D. and Others, "Some Dynamical Properties of the Savonius Rotor Current Meter," p.115-125 in Symposium on Tranducers for Oceanic Research, San Diego, California, 1962. Proceedings, Plenum Press, 1963

29. Hansen, P., "Note on the Omnidirectionality of the Savonius Rotor Current Meter," Journal of Geophysical Research, v.69, p.4419, 15 October 1964 
(Security classification of pille, body of abstract and indextme annopation must be entered when the overall report is classilied.

ORIGINA TING ACTIVITY (Corporate author)

Naval Undersea Warfare Center

San Diego Laboratory

Unclassified

San Diego, California 92152

FLOWMETERS IN SHALLOW -WATER OCEANOGRAPHY

4. OESCRIPTIVE NOTE5 (TYPE of report and inclusive dates)

Research and Development Report, September 1965 - June 1967

5. ALTHOR(S) (First name, middle initial, last name

J.R. Olson

\begin{tabular}{|c|c|c|}
\hline $\begin{array}{l}\text { 6. REPORT DATE } \\
11 \text { July } 1967\end{array}$ & $\begin{array}{c}\text { 7a. TOTAL NO. OF PAGES } \\
44\end{array}$ & $\begin{array}{c}\text { 76. NO. OF REFS } \\
29\end{array}$ \\
\hline 8B. CONTRACT OR GRANT NO. & \multicolumn{2}{|c|}{ 98. ORIGINATOR'S REPORT NUMGER(S) } \\
\hline $\begin{aligned} \text { b. PROJECTNO. } & \text { SR } 1040301 \\
& \text { Task } 0580\end{aligned}$ & \multicolumn{2}{|c|}{ TP 5} \\
\hline (NEL L40471) & \multicolumn{2}{|c|}{$\begin{array}{l}\text { 96. OTHER REPORT NO(S) (Any other numbers that may be as signed } \\
\text { this report) }\end{array}$} \\
\hline
\end{tabular}

10. DISTRIBUTION STATEMENT

This document has been approved for public release and sale;

its distribution is unlimited.

11. SUPPLEMEN.TARY NOTES

Naval Ship Systems Command

Department of the Navy

A study was conducted to determine the relative merits of various flowmeters and techniques used in shallow-water oceanography. Although problems still exist with the use of electromagnetic flowmeters, it was concluded that these represent the best medium for measuring steady-state currents at depths where the magnitude of orbital velocities caused by surface waves can be several times larger than steady-state flows. 
UNCLASSIFIED

Security Classification

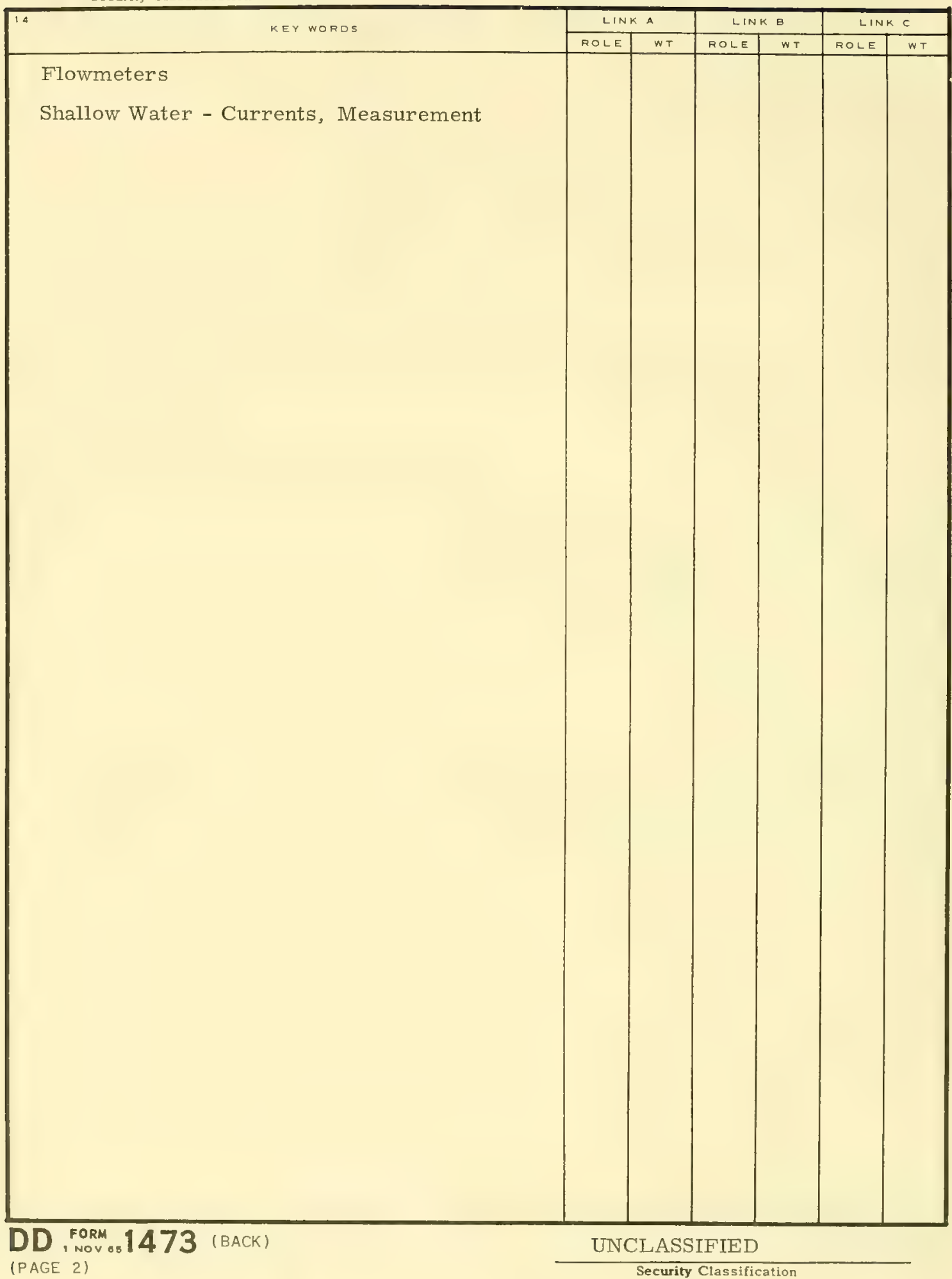






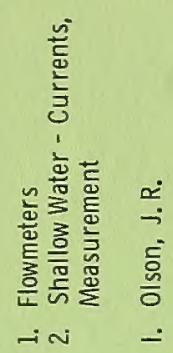

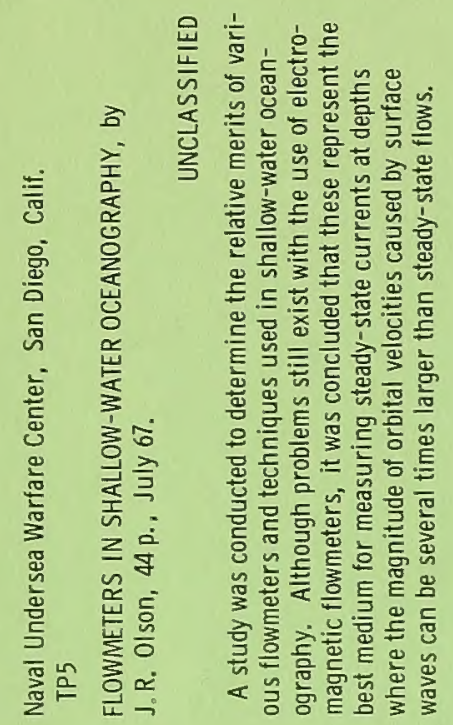

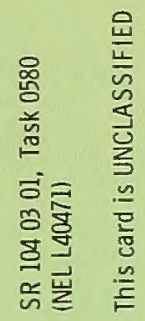

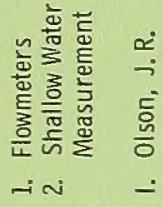

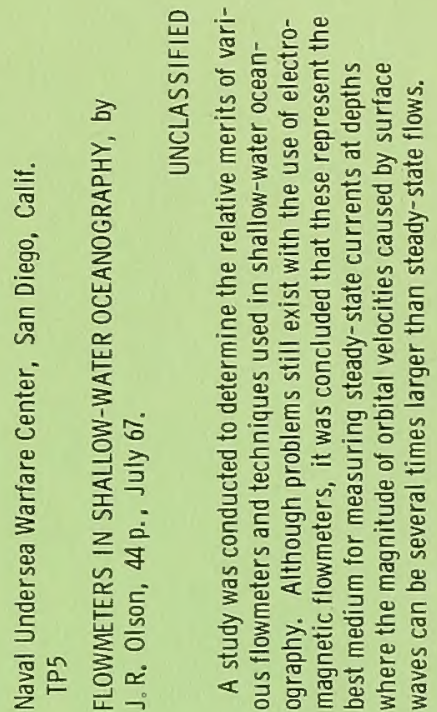

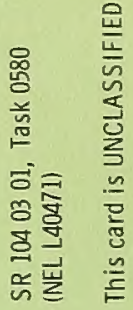

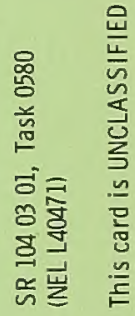

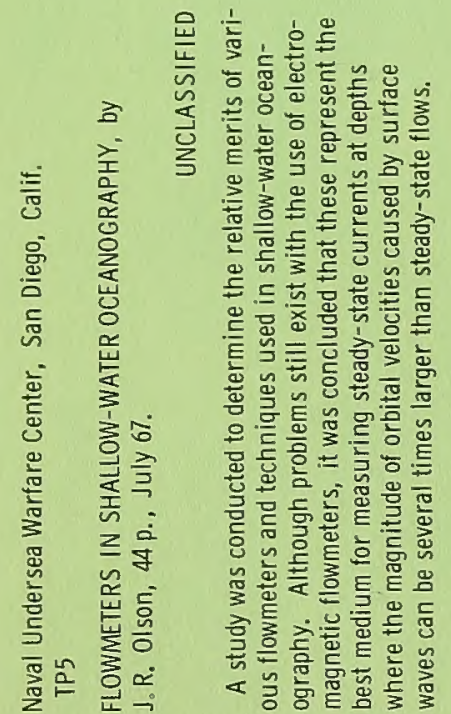

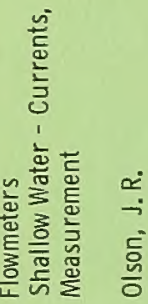

IN -

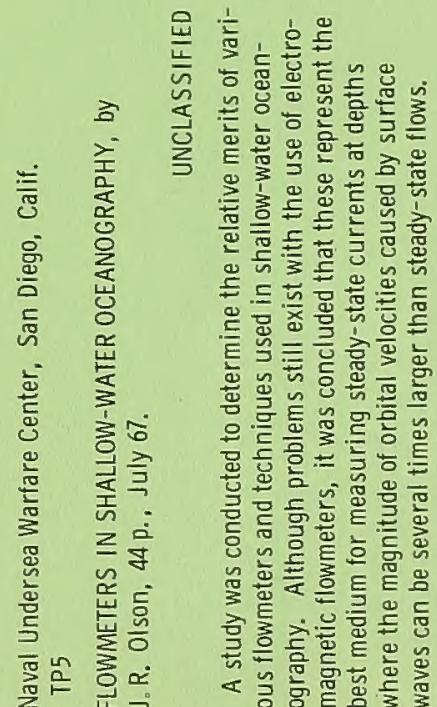


